\title{
Fiebre de baile. Los nuevos dancings comerciales y la transformación de los hábitos de ocio e interacción sexual de la juventud popular y obrera de Madrid (1918-1936)
}

\author{
Dancing craze. The new commercial dancings (dance halls) and the \\ transformation of the leisure habits and sexual interaction of the \\ working class youth in Madrid (1918-1936)
}

\author{
Cristina DE PEDRo Álvarez \\ Universidad Complutense de Madrid
}

\section{RESUMEN}

Esta investigación analiza la relación entre la consolidación de un nuevo mercado del ocio comercializado en el Madrid de entreguerras y la aparición de nuevas conductas y rituales de interacción lúdica y sexual entre los jóvenes de los barrios populares de la ciudad que participaban y socializaban en él a diario. A partir del análisis de documentación judicial relacionada con delitos de índole sexual, así como de anuarios comerciales y guías del ocio, se pretende valorar hasta qué punto los nuevos locales y entretenimientos baratos, y específicamente las nuevas salas de baile comercial, constituyeron la arena sobre la que se articularon y negociaron valores y comportamientos sociales y sexuales de nuevo cuño, sobre la que se expresaron y legitimaron nuevas nociones en torno a la sexualidad, el noviazgo y el flirteo.

\section{PALABRAs CLAVE}

Ocio; hábitos de entretenimiento; bailes comerciales; flirteo; sexualidad.

\begin{abstract}
This research analyses the relationship between the consolidation of a new commercial leisure market in interwar Madrid and the emergence of new behaviours and rituals of social and sexual interaction among working class young people who participated and socialized through it on a daily basis. Based on the analysis of judicial documentation related to sexual crimes, as well as commercial directories and leisure guides, the aim is to assess the extent to which the new cheap amusements, and specifically the new dance halls, constituted the arena in which new social and sexual values and behaviours were articulated and negotiated, and on which new notions of sexuality, courtship and flirting were expressed and legitimized.
\end{abstract}

\section{KEYWORDS}

Keywords: Leisure; Entertainment habits; Dance halls; Flirt; Sexuality. 
Dolores Domínguez y Matías Carrascosa se conocieron en 1921 en el baile de La Gruta. Un domingo de principios de diciembre, estando ambos en aquel dancing ubicado en la calle del Norte $n^{\circ} 9$, Dolores entabló conversación con el joven, quien ya el día anterior se había fijado en la muchacha en aquel mismo local, y decidió, ahora sí, dejar a un lado todas sus vergüenzas y acercarse a ella. La joven contaba entonces con 18 años y trabajaba como sirvienta en la calle de Ferraz $n^{\circ}$ 92, pero le gustaba moverse en sus ratos libres por los populares barrios de Quiñones y Amaniel, que conformaban, junto a sus colindantes, una de las zonas más animadas del casco viejo de Madrid para salir a divertirse. Matías, barbero de 26 años, vivía a escasos 500 metros de la sala de baile, donde se dejaba ver con frecuencia los domingos y festivos, y también algunas tardes entre semana. Después de compartir miradas, bailes y flirteos, Dolores y Matías acabaron aquella noche acostándose juntos en una casa de citas de la hoy desaparecida calle de Santa Margarita $\mathrm{n}^{0}$ 5, próxima a la Plaza de España. Días después, los muchachos se vieron de nuevo, yendo juntos a cenar a una taberna de la calle de San Bernardo, conocida entre los parroquianos con el nombre de La Marta por llamarse así la mujer que la regentaba. Allí Dolores bebió cerveza, "hasta el punto de embriagarse”, y después marchó con Matías a otra casa de recibir parejas alojada en el $n^{0} 50$ de la calle del Espíritu Santo, donde de nuevo, y como era habitual, la encargada Dolores Armenteros hizo la vista gorda ante la evidente minoría de edad de la joven y les permitió pasar la noche juntos a cambio del pago de una habitación. Dolores y Matías durmieron siete noches seguidas allí sin que la madre de ella, Josefa, tuviera noticia alguna, pues la creía sirviendo desde hacía un mes en la casa de la calle de Ferraz. Josefa andaba poco enterada de lo que hacía la muchacha, y lo mismo ocurría con su padre, quien las había abandonado a ambas nueve años atrás sin dejar rastro de su paradero.

La breve aventura amorosa de Dolores y Matías acabó dirimiéndose días más tarde en el Juzgado de Primera Instancia e Instrucción del distrito de Hospicio, donde se incoó un sumario judicial, gracias al cual hoy podemos contar esta historia. Al enterarse por su hija de lo ocurrido, Josefa dio inicio al procedimiento interponiendo una denuncia por violación contra el joven barbero en la Comisaría del distrito, donde aseveró, para justificarla, que aquél había empleado artimañas y engaños para seducir a su hija. Dolores corroboró la acusación, sosteniendo que se había acostado con Matías porque le había prometido casamiento, pero que, después de aquellas siete noches, el muchacho había desaparecido, y ella se decidió entonces a contárselo todo a su madre para proceder contra él. Pese a sus intentos, el litigio finalmente no llegó a nada, porque Matías desmintió la imputación y declaró que en la relación sexual no había mediado promesa alguna de matrimonio, y que, de hecho, Dolores estaba ya "deshonrada" cuando se acostaron juntos. No hubo prueba ni declaración que confirmara la versión de uno u otra: las encargadas de las casas de citas a las que acudieron negaron directamente que los muchachos hubieran estado allí, seguramente porque sabían que aceptar la entrada de una menor en aquel tipo de establecimientos suponía incurrir en un delito de corrupción de menores ${ }^{1}$. Los careos ordenados por el Juez tampoco resolvieron el conflicto, pues los protagonistas se mantuvieron firmes en sus declaraciones confrontadas. Solo dos reconocimientos médicos, uno de una Casa de Socorro a la que Josefa llevó a su hija antes de ir a Comisaría, y otro de los médicos forenses del Juzgado, confirmaron que, efectivamente, Dolores se encontraba "desflorada", certificando, no obstante, que no existían signos de que esto hubiera ocurrido

1. Así lo estipulaba el artículo 609 del Código Penal de 1870, vigente aún en 1921. 
recientemente. Sin más evidencias, el juez decidió sobreseer temporalmente el caso y dar por finalizadas las investigaciones ${ }^{2}$.

Ilustración 1: Recorridos de Dolores Domínguez y Matías Carrascosa (1921)

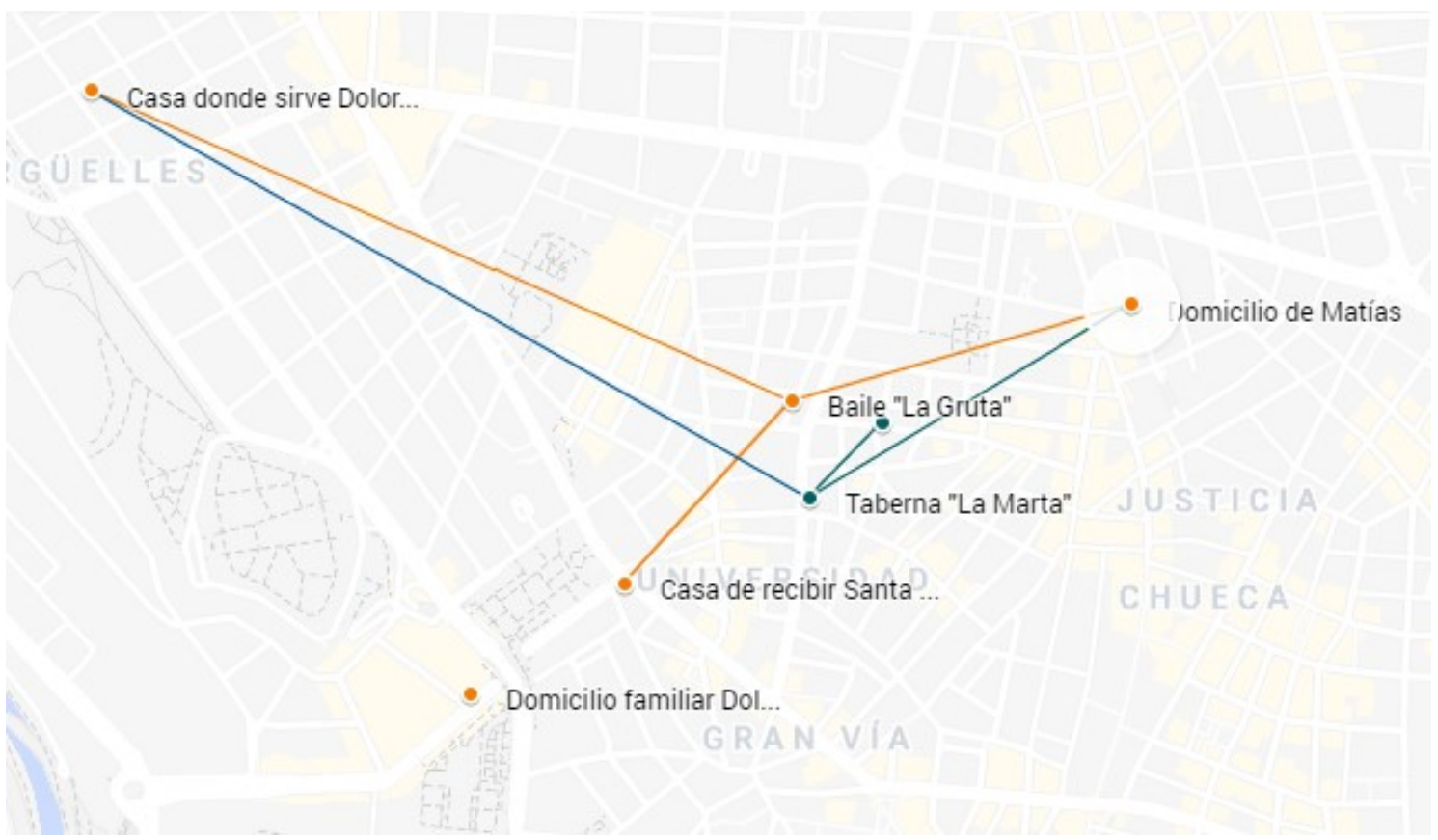

F.: Elaboración propia a partir de los datos obtenidos en AGA, Justicia, leg. (07) 041.006, caja 44/15472.

El litigio judicial que protagonizaron Dolores y Matías en el invierno de 1921 no constituye un caso aislado. Múltiples sumarios documentan historias y episodios que permiten entrever patrones de entretenimiento y formas de interacción social y sexual entre chicos y chicas de entornos populares muy similares a la iniciada por los dos muchachos en el baile de La Gruta. Estos pleitos acabaron igualmente en los juzgados, a menudo a raíz de denuncias de las madres de ellas, interpuestas ante la evidencia de un contacto sexual y, en la mayor parte de los casos (a diferencia de lo que ocurrió con Dolores), sin la connivencia de las hijas. Tampoco era un fenómeno exclusivo de la capital española, pues, según han puesto de manifiesto diversos estudios centrados en otras urbes occidentales, los conflictos intrafamiliares surgidos a raíz del contacto sexual prematrimonial entre jóvenes, consumado en muchas ocasiones tras salidas y periplos nocturnos por bares, bailes, cines y tabernas, se daban con frecuencia en los

2. Los detalles sobre la historia y el litigio judicial que siguió a la aventura amorosa de Dolores y Matías, en ARCHIVO GENERAL DE LA ADMINISTRACIÓN (en adelante AGA), Justicia, leg. (07) 041.006, caja 44/15472. 
vecindarios y barrios obreros durante los años de entreguerras ${ }^{3}$. El problema surgido en torno al ocio y la sexualidad juvenil traspasó incluso el umbral del hogar y la familia, y se convirtió en estas décadas en motivo de preocupación y debate público. Múltiples ciudades vieron nacer grupos y ligas que alentaron pánicos morales e impulsaron campañas, en prensa o a pie de calle, con las que trataban de ponerle freno a lo que consideraban uno de los principales problemas derivados de la vida urbana moderna: la degradación de las costumbres sexuales de la juventud en general, y en particular el pernicioso efecto que sobre su honestidad (la de ellas, fundamentalmente) ejercían los modernos locales de espectáculo y entretenimiento comercial como los cines, los bailes, los cafés-bar, los cabarets o los teatros baratos ${ }^{4}$.

Muchos contemporáneos coincidían en el diagnóstico: en sus discursos, los católicos y moralistas afirmaban que la gran ciudad (ya fuera Madrid, Barcelona, Bilbao, Londres, París, Berlín o Nueva York), rebautizada ahora como moderna Babilonia, era la responsable del desenfreno, el descontrol y el desorden moral y sexual de la juventud. Que era Madrid, en nuestro caso, el ente corruptor que estaba haciendo estragos en la moralidad y las buenas costumbres de los y las jóvenes, pues era allí donde estaban apareciendo y definiéndose nuevas prácticas y comportamientos sociales y sexuales. Aunque desde distinta óptica, estos argumentos coincidían con las apreciaciones que llegaban de la sociología urbana coetánea, en la medida en que ponían el foco en la responsabilidad que tenía la propia ciudad en la gestación de tales transformaciones. Veían a esta, no como un escenario inerte ajeno a estos cambios, sino

3. Para elaborar este texto, ee ha trabajado con otras investigaciones que han abordado el estudio comparado de discursos y construcciones normativas de género vinculadas a la sexualidad mediante testimonios personales extraídos de fuentes orales y procesos judiciales similares a los trabajados aquí: Nerea ARESTI, “El crimen de Trubia. Género, discursos y ciudadanía republicana”, Ayer, 64 (2006), pp. 261-285; ídem, Masculinidades en tela de juicio. Hombres y género en el primer tercio del siglo XX, Madrid, Cátedra, 2010; Miren LlONA, "Los otros cuerpos disciplinados. Relaciones de género y estrategias de autocontrol del cuerpo femenino (primer tercio del siglo XX)”, Arenal, 14, 1 (2007), pp. 79-108. Asimismo, se ha trabajado con estudios que abordan procesos similares en otras grandes ciudades del entorno europeo y americano, cuyas similitudes permiten entender lo que aquí se analiza como un fenómeno trasnacional y cosmopolita: Judith WALKOWITZ, Nights Out. Life in Cosmopolitan London, Yale University Press, 2012; Kathy PEISS, Cheap Amusements: Working Women and Leisure in Turn-ofthe-Century New York, Philadelphia, Temple University Press, 1986; Lola GonZALES-QuIJANO, Capitale de l'amour. Filles et lieux de plaisir à Paris au XIX siècle, París, Vendémiaire, 2015; Lewis A. EREnBerg, Steppin' Out. New York Nightlife and the Transformation of American Culture, Chicago, University of Chicago Press, 1984; Dominique KalifA, Paris. Une histoire érotique, d'Offenbach aux Sixties, París, Payot, 2018; Andrew I. Ross, Public City, Public Sex. Homosexuality, Prostitution and the Urban Culture in Nineteenth Century Paris, Philadelphia, Temple University Press; Chad HEAP, Slumming: Sexual and Racial Encounters in American Nightlife, 1885-1940, Chicago, University of Chicago Press, 2010; George CHAunCEY, Gay New York: Gender, Urban Culture and the Making of the Gay Male World, 1890-1940, Nueva York, Basic Books, 1994; Jill Suzanne Smith, Berlin Coquette. Prostitution and the New German Woman, 1890-1933, Nueva York, Cornell University Press, 2013.

4. Para el caso de Madrid, aparte de las campañas de prensa que pusieron en marcha periódicos y revistas como La Acción, El Siglo Futuro, La Unión Católica o la Revista Católica de Cuestiones Sociales, surgieron grupos y asociaciones como la Liga Antipornográfica, la Liga contra la Pública Inmoralidad o las Damas Catequistas, que no solo lanzaban acciones de propaganda a través de conferencias y congresos, sino que también actuaban en la calle, denunciando espectáculos de teatro o cabaret, censurando films cinematográficos, delatando a los dueños de los quioscos que vendían literatura erótica e incluso forzando bautizos y matrimonios en los barrios y vecindarios de origen popular. La actividad desplegada por las ligas ha quedado documentada en multitud de noticias volcadas a la prensa durante todo el período en que estuvieron en funcionamiento (la primera entre 1911-1912 y la segunda entre 1918-1930). Las misiones de las Damas Catequistas aparecen detalladas en su boletín oficial, Las Damas Catequistas y sus centros obreros. 
como un elemento clave, constitutivo de los mismos. De un modo u otro, con mayores o menores dosis de pánico o exageración, se formuló y sostuvo la que se ha convertido hoy en día en una de las premisas básicas de la nueva historia urbana surgida al calor del giro espacial y cultural, y sobre la cual se asienta el siguiente trabajo: la de entender la ciudad como una precondición necesaria para la emergencia de nuevas pautas y costumbres cotidianas y, en este caso, de nuevos hábitos y prácticas de interacción lúdica y sexual ${ }^{5}$.

Inscrito y deudor de una larga trayectoria de estudios que, bajo el paraguas de esta nueva historia urbana, ha puesto la atención en el análisis de la relación entre ciudad y sexualidad ${ }^{6}$, este texto busca observar y entender los sumarios y causas judiciales como la de Dolores y Matías a partir del espacio en el que acontecieron, centrando su atención en el dónde concreto y específico en que tuvieron lugar, esto es, en el Madrid de entreguerras. Se plantea reflexionar, más que sobre los procedimientos judiciales en sí o sobre la representatividad de los casos analizados, sobre las condiciones que hicieron posibles las prácticas y comportamientos que motivaron estos litigios; en definitiva, sobre lo que permitió o facilitó que Dolores y Matías, igual que otros tantos jóvenes, protagonizaran aquellas dos salidas nocturnas de diciembre de 1921, antesala de su contacto sexual.

Para ello se ha estudiado, por un lado, la conformación, en la capital, de la nueva red de locales y entretenimientos comerciales producto de la mercantilización de la infraestructura lúdica madrileña durante los años de entreguerras ${ }^{7}$. Concretamente, el

5. Una nutrida compilación de las propuestas de esta nueva historia urbana en Shane EWEN, What is Urban History?, Cambridge, Polity Press, 2016. Algunos de los trabajos más representativos de esta rama de estudios son: Harold J. Dyos (dir.), The Study of Urban History, Londres, Edward Arnold, 1968; Simon GunN y Robert MORRIS, Identities in Space. Contested terrains in the Western City since 1850, Ashgate, Aldershot, 2001; Leif JERRAM, Streetlife: The Untold History of Europe's Twentieth Century, Oxford, OUP Oxford, 2013. Un repaso más detallado sobre las distintas vertientes de esta nueva historia urbana y su todavía escaso desarrollo en España en Rubén PALLOL, "Deudas pendientes de la historia urbana en España”, Ayer, 107 (2017), pp. 287-302.

6. Un breve repaso a modo de estado de la cuestión sobre esta trayectoria de estudios en Matt Houlbrook, “Cities”, en H. G. Cock y Matt Houlbrook, Palgrave Advances in the Modern History of Sexuality, Nueva York, Palgrave McMillan, 2006, pp. 133-156; Jeffrey WeEKS, What is Sexual History?, Cambridge, Polity Press, 2016, pp. 46-48. Además de los ya señalados, algunos de los trabajos más representativos de esta tradición historiográfica son: Judith R. WALKOWITZ, La ciudad de las pasiones terribles. Narraciones sobre el peligro sexual en el Londres victoriano, Madrid, Cátedra, 1995; Frank MorT y Linda NEAD, Sexual Geographies, Londres, Lawrence \& Wishart Ltd, 2000; Gillian SwANSON, Drunk with the Glitter: Space, Consumption and Sexual Instability in Modern Urban Culture, Nueva York, Routledge, 2007; Frank MorT, Capital Affairs, London and the Making of the Permissive Society, New Haven, Yale University Press, 2010; Phil HubBARD, Cities and Sexualities, Milton Park, Routledge, 2012; Matt HoulBROOK, Queer City, London: London Club Culture 1918-1967, Londres, National Trust, 2017.

7. Del interés que ha suscitado en los últimos años el proceso de mercantilización del ocio dan buena prueba los dosieres titulados "La mercantilización del ocio” (Historia Social, 2001) y "Espectáculo y sociedad en la España contemporánea” (Ayer, 2008), que reúnen estudios de algunos de los principales especialistas en la materia. Para el caso concreto de Madrid, Nuria RoDríGuEZ, La capital de un sueño. Madrid en el primer tercio del siglo XX, Madrid, Centro de Estudios Políticos y Constitucionales, 2015; José María BÁEz, Fútbol, cine y democracia. Ocio de masas en Madrid, 1923-1936, Madrid, Alianza Editorial, 2012; Santiago DE Miguel, La Gran Vía de Madrid. Historia social de una ciudad extinta (1860-1936), Madrid, ACCI, 2017; ídem y Nuria RoDRÍGUEZ, "Modernización comercial y nuevas formas de ocio y consumo en el Madrid del primer tercio del siglo XX”, en Alejandra IBARRA, No es país para jóvenes, Vitoria, Instituto Valentín Foronda, 2012, pp. 1-22; Edward BAKER, Madrid cosmopolita. La Gran Vía, 1910-1936, Madrid, Marcial Pons, 2009. 
texto se centra en el examen de la red de dancings públicos de la ciudad, uno de los lugares que de manera más marcada fomentó el encuentro y la interrelación social entre jóvenes de clases populares, como Dolores y Matías. Su reconstrucción ha sido posible gracias al trabajo con distintas fuentes, entre ellas el Anuario general de España de 1935, la Guía Mencon. Madrid 1925, la Guía de Madrid de noche de 1935 y el Noticiero-Guía de Madrid del mismo año ${ }^{8}$ así como carteleras y anuncios de espectáculos, planos y licencias de apertura de los locales, y reportajes y artículos de opinión. También han sido estudiadas y recogidas quejas y peticiones vecinales en las secciones destinadas para tal fin de algunos periódicos de la época, así como las Ordenanzas Municipales de 1919 y los Reglamentos de Policía de Espectáculos de 1913 y 1935.

Por otro lado, el trabajo recupera las historias y vivencias recogidas en 37 expedientes judiciales (por delitos de rapto, violación, estupro o corrupción de menores), procedentes de distintos Juzgados de Primera Instancia e Instrucción de Madrid entre 1918 y 1931. Estos expedientes fueron instruidos a raíz de encuentros sexuales acontecidos en contextos en que sus protagonistas estaban participando en actividades de ocio (después de ir a un baile, durante la proyección de una película en el cinematógrafo, en los reservados de un restaurante, después de un paseo nocturno, en una visita a un merendero, etc.) y que retratan prácticas de entretenimiento y correrías nocturnas similares a las que protagonizaron Dolores y Matías. Con el estudio de estas causas se pretende ir un poco más allá de la mera reconstrucción de la infraestructura de ocio y baile comercial de la ciudad, y observar la forma de participación y el uso que de ella se hizo por parte de los jóvenes de los barrios populares madrileños. El objetivo es valorar hasta qué punto la mutación y mercantilización del ocio en la capital madrileña transformó los hábitos, rutinas y, en definitiva, la cultura del entretenimiento de la juventud popular, un aspecto totalmente desatendido por una historiografía del ocio español contemporáneo que aún no termina de trasladar sus análisis hacia los públicos, la recepción o el impacto en las vidas y costumbres de los individuos ${ }^{9}$.

Asimismo, a partir de los sumarios judiciales se intenta analizar el vínculo entre esa participación de la juventud en los nuevos bailes comerciales y la aparición de una amplia gama de conductas sexuales, hallada en la documentación (desde el cortejo formal que termina con un encuentro sexual planeado al flirteo y escarceo sexual despreocupado y desinteresado), que esta manifestaba cotidianamente en estos lugares. Lo que se busca es comprender hasta qué punto estos nuevos establecimientos de entretenimiento comercial, en consonancia con las propias condiciones de existencia de estos jóvenes, marcadas por su género y su adscripción social, funcionaron como lugares o marcos posibilitadores de estas conductas de nuevo cuño, esto es, como lugares en los que, por su naturaleza cosmopolita y por las propias dinámicas de interacción y autoexpresión que llevaban implícitas, se dieron las condiciones necesarias para que quienes acudían a ellos conformaran poco a poco, mediante su uso y

8. Las referencias completas son: Anuario general de España. Comercio, industria, agricultura, ganadería, minería, propiedad, profesionales y elemento oficial, Barcelona, Anuarios Bailly-Baillière y Riera unidos, 1935; Guía Mencon. 1925; Antonio Aullón, Guía Madrid de noche, Madrid, s. e., 1935; Noticiero-Guía de Madrid, Madrid, 1935. También se han utilizado los datos que ofrece la revista La Gaceta Galante en su número del 7-4-1932.

9. Un último y completo estado de la cuestión sobre la historiografía del ocio contemporáneo en España en Jorge URíA, "La historia del ocio y el contemporaneísmo español. Viejas y nuevas perspectivas”, en Marta GARCÍA y Sergio VALERO, Tejer identidades: socialización, cultura y política en época contemporánea, Valencia, Tirant lo Blanch, 2018, pp. 241-282. 
asistencia cotidiana, nuevos rituales de cortejo y flirteo. Esos nuevos hábitos culturales, en definitiva, contribuyeron a reformular, por un lado, los valores asociados a la participación femenina en el ocio y su derecho al disfrute y la realización personal, y, por otro, el rol que jugaba el sexo en los rituales y prácticas de ocio, así como en las nuevas formas de relación entre los géneros que empezaban a ver la luz en los entornos urbanos de entreguerras.

\section{Los nuevos dancings comerciales de Madrid}

De todos los entretenimientos comerciales que Madrid puso al servicio de la juventud popular, el baile fue, junto al cine, el pasatiempo que más fascinación generó. El baile jugó un rol de vital importancia en la heterosocialización de la nueva cultura del ocio, así como en la gestación de nuevos valores comunes sobre la sexualidad y las relaciones de género asociados a ella ${ }^{10}$. Igual que de cines, de cafés-bar o de nuevas cervecerías y salas de espectáculo, Madrid se había dotado en aquellos años de una amplia red de locales de baile que se llenaban a diario de jóvenes aficionados que rendían culto a la musa Terpsícore. Estos bailes eran la réplica madrileña de los cientos de dancings que en estos años se abrieron también en ciudades como París, Londres, Nueva York, Chicago o Berlín, de los que las salas españolas copiaban incluso el nombre y los apellidos: Folies Bergère, Dancing Palace, Royal Dancing. Igual que en el resto de ciudades modernas, en Madrid se bailaba entonces "más que nunca”, "en todo sitio", "a toda hora”, decían, y la juventud "atolondrada”, no tenía ya más horizonte en sus vidas que la de pasar la tarde zapateando en el dancing de moda ${ }^{11}$ :

¿Qué les importa a esas infinitas, innumerables muchedumbres de danzantes obstinados en parodiar a monstruos totémicos súbitamente y fantásticamente animados por el tam-tam africano o el jazz yanqui, el problema espiritual y estético de sus patrias respectivas? No les habléis de libros, ni de arte, ni de ciencia, ni de la naturaleza, ni de la moral, ni del hogar, ni del amor distinto a los flirteos en dancing o el cinema, las gradas del estadio y el asiento delantero del auto. A ellos lo que les importa es descoyuntarse el cuerpo, buscar la arritmia grotesca de las formas, obedecer las estridencias de lo que ya se nombra muy certeramente "un cok-tail de música"12.

Entre 1914 y 1935 existieron en Madrid, según consta en los anuarios comerciales y las guías del ocio consultadas, al menos 47 salas de baile, algunas de ellas abiertas al público a finales de la década de 1910, pero la gran mayoría inauguradas después de la Primera Guerra Mundial, a lo largo de los años 1920 y 1930. Para abrir uno de estos bailes públicos, el Reglamento de Policía de Espectáculos y las Ordenanzas Municipales establecían la obligatoriedad de obtener una autorización de la Dirección General de Seguridad, cuya determinación dependería de un informe técnico

10. Heterosocial se entiende aquí como relativo o que denota relaciones sociales mixtas.

11. Estas y otras menciones a la "fiebre" que desató el baile en Madrid en Crónica, 25-12-1932 y 22-11934; El Heraldo de Madrid, 30-1-1933; El Imparcial, 30-1-1919; Estampa, 6-6-1931 y 15-1-1929; Mundo Gráfico, 16-2-1929; Nuevo Mundo, 22-10-1926, 4-3-1927, 29-4-1927, 11-10-1929; La Escuela Moderna, 11-1-1919. El desarrollo de esa locura por el baile, lo que ha sido llamado Dance Madness o Dance Craze en la bibliografía anglosajona, fue un fenómeno común a distintas ciudades modernas europeas y americanas en el período de entreguerras; así lo han puesto de manifiesto distintos especialistas: PEISS, Cheap Amusements, pp. 88-114; WALKOWITZ, Nights Out, pp. 190-194; ERENBERG, Steppin' Out, pp. 146-175; GonZALEs-QuiJAno, Capitale de l'amour, pp. 165-187; Kalifa, Paris. Une histoire érotique, pp. 57-68; Ross, Public city, Public sex, pp. 200-210.

12. Nuevo Mundo, 22-10-1926.

Rubrica Contemporanea, vol. X, n. 19, 2021 


\section{DE PEDRO}

realizado por un arquitecto municipal donde constase si el local reunía o no las condiciones de seguridad y salubridad necesarias. Por otro lado, en el caso de los bailes que no estuvieran alojados en locales específicamente destinados a espectáculos públicos, la concesión de la licencia dependería del resultado de un expediente en el que se incorporaran las consideraciones de los vecinos de los restantes pisos de la casa en la que se iba a ubicar la sala de baile, así como de los que habitaban las dos laterales de la misma y las tres de enfrente. Finalmente, a dicho expediente se aportaría el informe de los correspondientes funcionarios de Investigación y Vigilancia, indicando “clara y precisamente" si debía concederse o no el permiso solicitado ${ }^{13}$.

Ilustración 2: Salas de baile de Madrid (1918-1936)

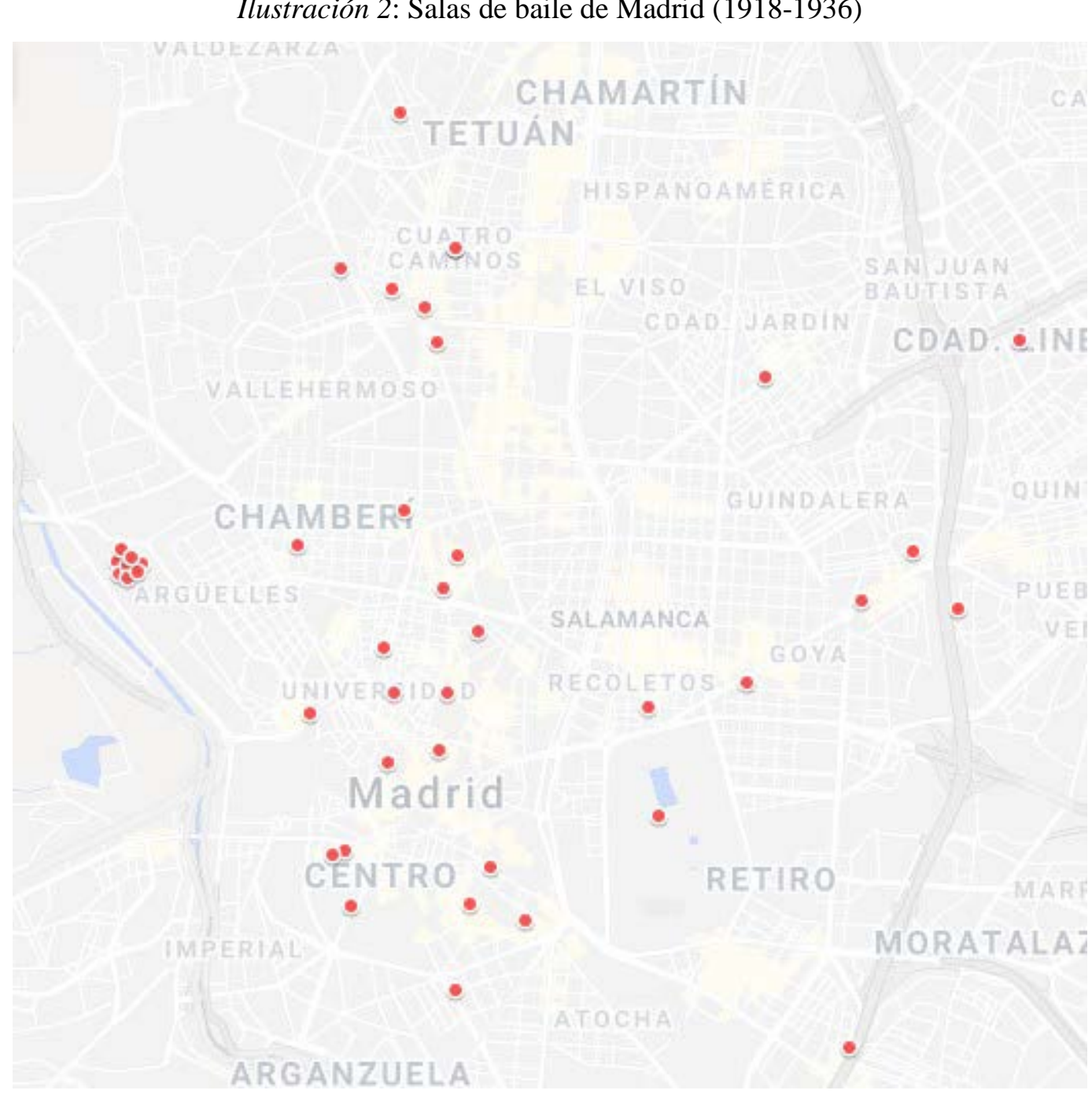

F.: Elaboración propia a partir de los datos obtenidos en Guía Mencon (1925), La Gaceta Galante, 7-4-1932, Anuario general de España (1935) y Guía Madrid de noche (1935).

La ubicación de estas salas de baile en la ciudad respondía a la procedencia eminentemente popular de la clientela que acudía cotidianamente a ellas, lo que hacía que se concentraran predominantemente en los barrios obreros del norte y del sur del

13. Reglamento de policía de espectáculos, Madrid, Imp. Municipal, 1913; "Reglamento de policía de espectáculos públicos”, La Gaceta de Madrid, 5-5-1935; Ordenanzas municipales de la Villa de Madrid, Madrid, Imprenta Municipal, 1919. 
casco viejo, así como en los suburbios del norte y el este del extrarradio de la ciudad ${ }^{14}$. Estos dancings, como fueron llamados entonces, eran locales cerrados en los que a diario por las tardes, y los domingos y festivos durante todo el día, se organizaban bailes llamados a veces populares o de modistillas, animados por la música de un organillo o gramófono, o de una moderna orquesta de tango o jazz band. Existían, en general, dos tipos de salas: algunas eran simples locales arrendados durante una temporada para acoger bailes populares de tarde o de noche, pero que a su vez se alquilaban también para combates de boxeo, reuniones de asociaciones, veladas, mítines, actos de campaña o cualquier otro tipo de jornada o reunión social. Otras, sin embargo, eran salas de cabaret que, antes de su espectáculo nocturno de varietés y souper tango (que solía empezar en torno a las diez u once de la noche), por las tardes organizaban sesiones de este otro tipo de bailes para la juventud, anunciados a veces en sus carteleras como "tébaile", "thé dansant" o "tea dancing" (pues recogen la costumbre instaurada ya en Francia e Inglaterra de organizar bailes a la hora del té), lo que daba más rentabilidad a su negocio ${ }^{15}$.

Los primeros solían ser salas o pabellones modestos que contaban casi exclusivamente con una tarima de parqué como pista del baile y bancos corridos de madera a ambos lados, además de un pequeño tablao en alto para la banda o la orquesta y un improvisado ambigú para el despacho de bebida y comida. Salas de este tipo eran la del baile El Fourquet, en la calle del Dr. Fourquet $\mathrm{n}^{0} 3$; el baile Embajadores, en la calle Embajadores $\mathrm{n}^{\circ}$ 63; el baile Ideal Polistilo, en la calle Villanueva $\mathrm{n}^{\circ}$ 28; el baile Casa Angulo, en la calle Almansa $\mathrm{n}^{\circ}$ 50; el baile Palacio de la Danza, en la calle Antonio Pirala $n^{\circ}$ 16; el Novelty, en Santa Engracia ${ }^{\circ}$ 154; el Recreo Magallanes, en la calle Magallanes $\mathrm{n}^{\circ}$ 17; el Biarritz, en López de Hoyos $\mathrm{n}^{\circ} 71$; el Salón España en la calle Arregui y Arruej; el Salón Madrid Bohemio, en la calle del Humilladero $n^{\circ}$ 19; el Trouville, en la calle de Fuencarral $n^{\circ} 118$; o el baile de La Gruta, en la calle del Norte $\mathrm{n}^{\text {os }} 9$ y 10, entre otros. Sin embargo, los bailes que funcionaban por la noche como salones de cabaret contaban con un mejor avituallamiento. Eran locales más grandes, a veces con varias salas, guardarropa, palcos y un servicio completo de bar. La mayoría disponían de un escenario para la jazz band y de una amplia pista de baile rodeada con divanes y mesas, engalanada con juegos de luces, espejos, alfombras, cortinajes y otros elementos decorativos ${ }^{16}$. Entre estos estaban el Palacio de Terpsícore (llamado después El Búho Rojo), en la Costanilla de San Pedro n ${ }^{\circ}$ 6; el Forteen Club (llamado después Excelsior), en la calle del Barco nº 34; el Folies Bergère (llamado después El As y

14. Sobre la conformación de nuevos distritos de ocio alternativos a la Gran Vía y la Puerta del Sol en los barrios popular del casco viejo de la ciudad, Rubén PALLOL y Cristina DE PEDRO, "Madrid Nightlife and Popular Leisure. Between Globalizing Cosmopolitanism and Social Transgression”, en Antje DIETZE y Alexander VARI, Cultural Transfers and Exchanges: Popular Entertainments in Northern, East-Central and Southern Europe, 1870s-1930s (en prensa).

15. También había algunos dancings instalados en salas habilitadas para el baile de algunos restaurantes, como por ejemplo el baile Faro de Londres (calle Dr. Santero ${ }^{\circ} 2$ 2), Los Cipreses o el más famoso de Casa Juan, los dos últimos situados en la Bombilla. Esta información sobre los distintos tipos de locales y sus sesiones de tarde y de noche ha sido extraída del estudio de la programación y las carteleras de algunos de estos establecimientos durante el periodo 1918-1936, concretamente las del Folies Bergère, Palacio de Terpsícore, El Fourquet, Ideal Polistilo, Forteen Club, Trouville y el Barbieri.

16. Los detalles del mobiliario e instalaciones de algunos de estos bailes en AGA, Justicia, leg. (07) 041.008, caja 44/16184; (07) 041.007 Top. 43/29,101-29, 203 caja 5485 (Cabaret Barbieri); La Voz, 246-1925 (Palacio de Terpsícore); La Libertad, 26-8-1922; La Voz, 2-11-1922 (Folies Bergère); La Correspondencia de España, 27-1-1919; La Voz, 9-11-1927 (El Fourquet); El Liberal, 1-3-1931 (Forteen Club); El Imparcial, 29-6-1918; La Libertad, 1-3-1931 (Ideal Polistilo). 
posteriormente Royal Dancing), en la calle de Andrés Borrego ${ }^{\text {os }} 8$ y 10; el Barbieri (llamado un tiempo A.B.I. Parisien y después Fantasio), en la calle de la Primavera $\mathrm{n}^{\circ}$ 7; el Taxi Apolo, en la calle de la Salud n ${ }^{\circ} 18$; el Satán, en la calle de Atocha $\mathrm{n}^{\circ} 60$ o el Dancing Palace, en la Travesía de Trujillos $\mathrm{n}^{\circ} 2$.

La afición al baile de la juventud popular madrileña no era un fenómeno exclusivo de los años de entreguerras. Ya en 1900 el baile formaba parte del ritual adscrito al ciclo estival de verbenas, y con mucha frecuencia se organizaban también bailes al aire libre en las zonas de merenderos de la ciudad, ubicados principalmente en los parques y descampados ${ }^{17}$. Por otro lado, las familias y vecinos de los barrios populares alquilaban a menudo locales para celebrar reuniones, veladas, fiestas, bodas o cualquier otro evento puntual y privado, en los que se celebraban bailes donde participaban todos los miembros de la familia y que jugaban un papel clave en la gestación y refuerzo de los lazos y vínculos afectivos dentro de la comunidad. En algunos casos, estos locales, que en la década de los diez fueron arrendados por los vecinos para organizar bailes y celebraciones familiares, fueron los mismos que años después se destinaron a establecer salas de baile comercial y cabaret. Por ejemplo, el dancing Folies Bergère, fue previamente alquilado en 1909 para "celebrar reuniones familiares y establecer un ambigú (un pequeño bar) para uso exclusivo de los socios”, según consta en la licencia de apertura que le fue concedida por el Ayuntamiento al vecino de la cercana calle de los Reyes, Valeriano García ${ }^{18}$. Posteriormente, en 1919, el empresario Vicente Martínez solicitó una nueva licencia de apertura, esta vez a la Dirección General de Seguridad, por tratarse, ahora sí, de un local destinado a organizar bailes públicos “diariamente, por la tarde y noche”, es decir, abierto para todo el mundo a cambio del pago de una entrada ${ }^{19}$. De esta transformación de los bailes madrileños de principios de siglo hubo quien, como con todo, se lamentó. Así lo hizo José Montero Alonso en un escrito titulado "Los últimos merenderos":

El merendero con su esplendor, su literatura y su novelería, está unido a un momento de la vida de Madrid que no es, naturalmente, el de ahora. El merendero pertenece, desde luego, al Madrid de avant-guerre... el de 1905, de 1908, de 1912 [...]. El merendero es de entonces, de los días en que triunfaban la manuela castiza, el chotis chulón, las patillas postineras y el mantoncito de crespón negro [...]. Pero llegó aquel agosto de 1914. La música lenta y dulce de los valses vieneses fue apagada por el trágico estampido de los cañones. Sobre Madrid empezó a caer el aluvión de la guerra. Y Madrid fue cambiando, rápida y profundamente, y en 1918, cuando sobre el suelo de Europa cesaban en su lúgubre cabalgada los cuatro jinetes apocalípticos, Madrid era una ciudad nueva, una capital distinta a aquella que hasta 1914 fue... A partir de entonces el merendero cambió su nombre por el de dancing. En la Bombilla, antes sede triunfal de los merenderos, el organillo quedó arrinconado, vencido por las nuevas orquestas con jazz-band. Se marcharon los mantones, llegaron las primeras melenas cortas, el chotis y la habanera -ritmos lentos, ceñidos, de zumbona seriedad- se bailaron menos que el tango argentino y que el fox inglés... El simón y la mañuela cayeron en su irremediable ocaso. Todo cambió, inexorablemente... el merendero quedó también envuelto en las nieblas del Madrid que se iba. Así, al cabo de unos años, de los bailes castizos de Provisiones, la Costanilla y La Rosa Blanca no quedaba más que un recuerdo. El madrileñísimo baile de la Costanilla se convertía en el Palacio de Terpsícore [...] Florecieron el The Forteen Club, el Folies Bergère, el Dancing Bombilla... Los viejos bailes y merenderos quedaban convertidos

17. Carmen DEL MoRAL, “Ocio y esparcimiento en Madrid hacia 1900”, Arbor, 169 (2001), pp. 506-509 (https://doi.org/10.3989/arbor.2001.i666.894).

18. ARCHIVO DE LA VILLA DE MADRID (AVM), exp.: 17-229-61.

19. AVM, Exp.: 23-204-173.

Rubrica Contemporanea, vol. X, n. 19, 2021 
en unos flamantes y vistosos dancings con muchas luces de colores y mucho ruido de jazzband $^{20}$.

Los modernos bailes comerciales que aparecieron en Madrid a partir de los años de entreguerras no solo ampliaron y diversificaron la oferta de lugares para bailar, sino que modificaron las propias lógicas de organización y funcionamiento que habían definido a los bailes tradicionales. El dancing, decía la revista Crónica en octubre de 1932, "es hoy una gran industria, en el verdadero sentido de la palabra" ${ }^{21}$, y como tal funcionaron los diversos ejemplares de esta nueva forma de entretenimiento mercantilizado que la ciudad puso a disposición de la juventud. Para empezar, la programación de los nuevos bailes comerciales ya no estaba adscrita exclusivamente a celebraciones y fechas específicas del calendario, como ocurría con las verbenas o con los tradicionales bailes de Carnaval. Como explicaba la revista Estampa a una lectora ficticia, estos se sucedían durante todo el año y todos los días de la semana:

No hace muchos años, señorita, los bailes eran festejos excepcionales que se celebraban en tres o cuatro fechas señaladas. Una muchacha soñaba con tan gran acontecimiento durante meses enteros [...]. ¿Quién iba a sospechar, entonces, que esas reuniones familiares iban a transformarse en unos festejos diarios, donde gentes que no se conocen se abrazan al compás de todos los motivos musicales del mundo? ${ }^{22}$

Ir al baile, como ir al cine o al cabaret, ya no era un evento extraordinario anexo a una fecha señalada, pues como actividad de ocio moderno esta había sido ya plenamente incorporada a los ciclos y tiempos cotidianos del día y de la semana. Las carteleras de estos dancings comerciales informan de la programación de bailes todos los días por las tardes, en un horario que daba inicio entre las $16.00 \mathrm{y}$ las $18.00 \mathrm{y}$ finalizaba entre las 20.00 y las 22.00. Los domingos y festivos, a veces, los locales de baile celebraban sesiones continuas de bailes de modistillas desde la mañana a la tarde, y algunos de los locales que funcionaban también como cabaret reservaban el local en exclusiva para ese cometido. Lo excepcional ahora ya no era en sí la propia celebración del baile, sino las fiestas, eventos especiales o "asombrosos acontecimientos" que se celebraban de cuando en cuando, y que rompían un poco ese ciclo cotidiano y semanal, como las fiestas de reapertura de algún local tras su reforma, los bailes temáticos o los días de gala, que podían ser martes, jueves o viernes, daba igual, porque de lo que se trataba era de atraer más público y clientela. La semana de Carnaval, por otro lado, seguía siendo el principal evento danzante del año, y todos los dancings preparaban programaciones especiales de bailes de disfraces y máscaras con piñatas y regalos ${ }^{23}$.

Tal era la pasión por la danza que en la capital empezaron a aparecer academias de baile para enseñar a manejarse a los madrileños en lo que era ya un requisito indispensable para el divertimento y el éxito amoroso. "No saber bailar", decía Nuevo Mundo en 1929, "puede equivaler a una absurda derrota íntima. Actualmente, hay que saber bailar”. Según el Anuario General de España, en 1935 existían en Madrid 12

20. La Esfera, 11 de julio de 1925. Otros testimonios parecidos en: Estampa, 31 de julio de 1928; La Voz, 9 de agosto de 1930; Nuevo Mundo, 1 de enero de 1932; El Imparcial, 20 de agosto de 1926; Buen Humor, 3 de mayo de 1925.

21. Crónica, 9-10-1932.

22. Estampa, 30-11-1933.

23. Toda esta información ha sido extraída del análisis de las carteleras de algunas de estas salas de baile en el periodo 1918-1936, concretamente las del Palacio de Terpsícore, el Forteen Club, el Folies Bergère, el Trouville, el Ideal Polistilo, el Faro de Londres, el Fourquet y el Barbieri; también de Guía Mencon. Madrid 1925..., pp. 145-146. 
academias de baile, ubicadas en distintos puntos de la ciudad, la mayoría en el centro

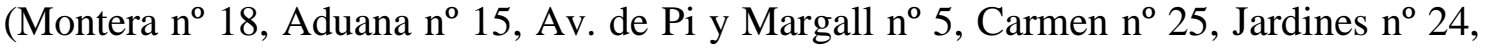
Eduardo Dato $\mathrm{n}^{\circ}$ 8, Montera $\mathrm{n}^{\circ} 18$ y 24), pero también en los distritos populares del norte y el sur (Encomienda $\mathrm{n}^{0} 10$, Fuencarral $\mathrm{n}^{0}$ 77) $\mathrm{o}$ en barrios intermedios (Concepción Jerónima $\mathrm{n}^{\circ}$ 10, Plaza de Santa Ana $\mathrm{n}^{\circ}$ 17). La afición por aprender el arte de la danza crecía cada día en la ciudad, a la par entre muchachos y muchachas, algunos de los cuales acudían a estas academias para adquirir las dotes que les permitieran después desenvolverse bien en la pista de baile. Lo más solicitado, decían, era el tango argentino y los bailes americanos, el fox y el black-bottom, a los que seguían después el chotis, el vals y el pasodoble ${ }^{24}$. También aparecieron campeonatos de baile, protagonizados por parejas de profesionales que eran profesores o se habían formado previamente en estas academias. La revista Crónica realizó dos reportajes en 1931 y 1933 sobre dos campeonatos de resistencia celebrados en el Circo de Price, en los que las parejas competían durante semanas para ver cuál aguantaba las mil horas de baile que exigía el reglamento sin quedar descalificada ${ }^{25}$. Asimismo, los nuevos dancings también organizaban de vez en cuando concursos de baile, a los que acudían bailarines profesionales para dar una lección a los jóvenes aficionados. Normalmente, después de la exhibición de los expertos, daba comienzo el concurso de los neófitos. Los había de todo tipo: de vals, de polka, de blues, de fox ${ }^{26}$.

Más allá de su programación continua, la característica que definió principalmente estos nuevos dancings e hizo que se convirtieran en centros esenciales de encuentro, sociabilidad e interacción entre los chicos y chicas de las clases populares, fue que se trataba de establecimientos públicos. Para acudir a los nuevos bailes comerciales, ya no era necesario ser miembro de ninguna sociedad ni presentar una invitación personal, como ocurría en los bailes familiares o en los llamados bailes de sociedad o aristocráticos que organizaba la burguesía y las capas adineradas de la ciudad en locales propios o en grandes teatros, circos u hoteles exclusivos ${ }^{27}$. El acceso a estas salas de baile, ahora, solo requería el pago de una entrada, cuyo coste en general era bastante reducido, lo que les hizo ganarse el apelativo de dancings democráticos ${ }^{28}$. Según informan las guías del ocio, así como las carteleras de algunas de estas salas, frecuentemente el precio de la entrada no era el mismo para ellas que para ellos. Por ejemplo, en 1925, la entrada al baile que se celebraba en el Barbieri costaba 2 pesetas para los muchachos mientras que para ellas era gratuita. Lo mismo ocurría en el Forteen Club, en el Faro de Londres (1 peseta para ellos), en el Franco-Español (1,50 pts. para ellos), en el Palacio de Terpsícore (1,50 para ellos) o en el baile La Huerta (1 peseta para ellos). En otros, la entrada para ellas no era gratis, pero sí mucho más barata, como ocurría en el Ideal Polistilo, donde el acceso les suponía a los muchachos 2 pesetas y a ellas a 0,50. En otros casos, el precio era el mismo para ellos que para ellas, y podía

24. Nuevo Mundo, 12-4-1929; Crónica, 3-5-1931.

25. Crónica, 27-12-1931 y 22-1-1933; El Heraldo de Madrid, 30-1-1933.

26. La Libertad, 15-3-1921, 28-2-1922 y 15-2-1924; La Voz, 3-2-1925; El Heraldo de Madrid, 18-71930.

27. Sobre los lugares y el funcionamiento de estos bailes de sociedad, Nuevo Mundo, 11-8-1933; Alrededor del mundo, 7-2-1921; Crónica, 18-2-1934; Del Moral: “Ocio y esparcimiento”, pp. 506-509.

28. Así se refiere la revista Nuevo Mundo a los nuevos “dancings democráticos de las modistas” que sustituyeron a los típicos bailes de antaño en Madrid (15-10-1926). 
rondar entre 0,50 y 2 pesetas o simplemente el coste mismo de la consumición, como ocurría en el Folies Bergère, en el Niza o en el Ciudad Lineal ${ }^{29}$.

Los empresarios y gestores de estos dancings establecían estos precios reducidos para atraer el mayor número de gente, conscientes de que la juventud popular no podía permitirse grandes dispendios. Fue esta misma lógica la que fomentó, precisamente, la presencia de ellas, de las chicas jóvenes de clases populares, primero porque estas disponían de un remanente mucho más escaso para gastarlo en actividades de ocio, y segundo porque promover la presencia femenina en estos bailes servía para atraer, a su vez, al público masculino. La propia naturaleza comercial de estas salas de baile instigó, pues, el encuentro y la mezcla heterosocial entre jóvenes de distinto sexo, estimulando así una ruptura fundamental en lo que respecta a las pautas que habían definido las prácticas y rituales de recreo popular en las décadas previas, cuando el ocio mercantilizado no había aterrizado aún en la capital. Eran tiempos caracterizados, para ellas (pues ellos disponían de la taberna ${ }^{30}$ ), por la casi ausencia de lugares públicos de recreo más allá de la propia calle, en los que predominaban pautas de entretenimiento y sociabilidad informal contenidas mayoritariamente en los estrechos contornos del vecindario inmediato y muy vinculadas a las faenas domésticas y los compromisos y celebraciones familiares, vecinales o religiosas ${ }^{31}$. Ahora, sin embargo, el rédito comercial que generaba la presencia femenina en los nuevos dancings democráticos estaba instigando y haciendo efectiva, a la par que legitimando, la participación de las jóvenes en el ocio público, además de fomentar el encuentro y la coincidencia de ambos sexos en los mismos lugares de entretenimiento ${ }^{32}$. Ahora chicos y chicas disponían de nuevos lugares para encontrarse e interactuar, y ello, como vimos con Dolores y Matías, podía favorecer la aparición de distintas formas de interacción erótica y sexual.

A los bailes se acudía, pues, a bailar y divertirse, pero también a encontrarse con el otro, un otro que, además, ya no tenía por qué ser conocido, pues ya no era necesariamente un vecino del mismo barrio. Como ya vimos con Dolores y Matías, estos locales atraían a chicos y chicas de distintas partes de la ciudad: Mercedes Domau, por ejemplo, acudió la tarde del 17 de noviembre de 1924 al baile del Angulo, sito en la calle Almansa y muy próximo a su domicilio de la calle de las Carolinas $\mathrm{n}^{\circ} 15$, donde conoció a un muchacho que la llevó después a bailar con unos amigos a Las Ventas y a quien, según dijo después, no conocía de nada, solo sabía que vivía por Puente de Vallecas. Asimismo, la joven Ana Grimaldo, que vivía en la calle de Ledesma, en el

29. Los precios de las entradas en Guía Mencon. Madrid 1925, Madrid, Industrial Gráfica, 1925, pp. 145146; La Libertad, 8-5-1927; La Voz, 18-2-1928; El Heraldo de Madrid, 29-2-1935.

30. Jorge URÍA, “La taberna: un espacio multifuncional de sociabilidad popular en la Restauración española”, Hispania, 63 (2003), pp. 571-604 (https://doi.org/10.3989/hispania.2003.v63.i214.225).

31. Los estudios sobre las formas de recreo de las mujeres de las clases populares urbanas son, todavía hoy, un asunto pendiente en la historiografía española contemporánea, especialmente en lo que concierne a periodos previos a los años de entreguerras. Algunas aproximaciones a la materia procedentes de fuera de nuestras fronteras, no obstante, permiten intuir las dinámicas arriba señaladas: PEISS, Cheap Amusements, pp. 11-33.

32. Sobre la creciente participación de las mujeres en el ocio público urbano durante los años de entreguerras se han realizado algunas investigaciones epidérmicas: Nerea ARESTI, "La mujer moderna, el tercer sexo y la bohemia en los años veinte”, Dossiers Feministes, 10 (2007), pp. 173-185; María Dolores RAMOS, "La modernidad que viene. Mujeres, vida cotidiana y espacios de ocio en los años veinte y treinta”, Arenal. Revista de historia de las mujeres, 14, 2 (2007), pp. 265-289; Jordi LuENGO, Gozos y ocios de la mujer moderna. Transgresiones estéticas en la vida urbana del primer tercio del siglo XX, Málaga, Servicio de Publicaciones de la Universidad de Málaga, 2008. 
extrarradio este de Madrid, entabló conversación y baile en el dancing El Fourquet (calle del Dr. Fourquet $n^{\circ} 3$ ), con Francisco Torres, cuyo domicilio se hallaba en la calle de Luis Villa, en uno de los nuevos barrios del ensanche este ${ }^{33}$. La proliferación de estos dancings por distintos puntos de la ciudad animó a los y las jóvenes a aventurarse fuera de sus vecindarios, a moverse en busca de nuevos lugares para divertirse, a encontrarse e interactuar con desconocidos y caras nuevas, incluso aunque pertenecieran a familias y vecindarios más pudientes. La prensa y la literatura de la época está plagada de referencias a los habituales encuentros y desencuentros entre estudiantes acomodados y modistillas en estos locales, y algunos de ellos han saltado también a la documentación judicial. El joven Claudio Pardo, por ejemplo, (Conde de Aranda $n^{\circ}$ 9), se dejaban caer por los bailes comerciales de Madrid para coquetear con modistas como Josefa García (Mesón de Paredes $n^{0} 58$ ), y otras jóvenes trabajadoras. Como le ocurrió a él con Josefa, estos flirteos derivaban a veces en posteriores citas y encuentros amorosos $^{34}$.

El propio hecho de que muchachos y muchachas se desplazaran, para salir, fuera del entorno inmediato del vecindario les otorgaba per se la posibilidad de actuar y comportarse sin sentir el peso y las restricciones que con frecuencia imponía la mirada paterna o materna. Salir a divertirse por los distintos locales de recreo que se ofrecían en Madrid estaba provocando, en efecto, que los jóvenes empezaran a disfrutar de una esfera de experiencia autónoma al margen de sus mayores en su tiempo de ocio. Pero es que, además, lo que tenían de particular los dancings respecto a otro tipo de bailes no comerciales que se organizaban en la ciudad, más allá de celebrarse a diario y estar abiertos para todo aquel que pagase la entrada, es que aquellos eran precisamente refugio exclusivo de la juventud. Los y las jóvenes se habían encontrado tradicionalmente en parques, verbenas e incluso en los cafés de barrio, a los que acudían acompañados de sus familias. También se encontraban e interactuaban en los bailes familiares y de vecindad que se organizaban en los merenderos ${ }^{35}$. Sin embargo, en los nuevos bailes comerciales lo hacían a solas, con la libertad y espontaneidad de quien no está siendo observado ni controlado. Como decía la revista Estampa, en los nuevos dancings "faltan aquellas magníficas mamás de antaño que soñaban con planes matrimoniales contemplando a Pepín y a Maruja, que hacían muy buena pareja. Hoy pocas mamás se reúnen para hablar de proyectos de boda y de los tiempos que pasan [...] ¡Maravillosas y comprensivas mamás-platino de hoy!”36.

Como demuestran también los sumarios judiciales, las muchachas acostumbraban a ir al baile solas o con amigas y compañeras, y allí encontraban a otros muchachos, conocidos o desconocidos, que en ningún caso iban acompañados por sus mayores. Ya vimos que Mercedes Domau salió sola de su casa para ir al baile El

33. AGA, Justicia, leg. (07) 41.010, caja 8.289, y Top: 43/37.606-38.309, caja 7.644.

34. Los casos judiciales trabajados en esta investigación solo recuperan un amorío entre estudiantes y modistillas, mientras que el resto de los y las jóvenes que los protagonizan provienen de entornos populares y obreros. No obstante, existen algunos trabajos que abordan este tópico: Miren LLONA, "La realidad de un mito. La aspiración de ascenso social de las 'modistillas', en el Bilbao de los años veinte y treinta”, Asparkia, 14 (2003), pp. 139-166; ídem, “Los otros cuerpos disciplinados”; Adela NúÑEZ, “Modistillas de Madrid, tradición y realidad”, en Luis Enrique OTERo y Ángel BAHAMONDE, La sociedad madrileña durante la Restauración: 1875-1931, Vol. II, Madrid, Comunidad de Madrid, 1989.

35. DEL MORAL, “Ocio y esparcimiento”, pp. 504-509.

36. Estampa, 16-2-1935. Otra mención a la ausencia de las madres en los dancing en La Esfera, 1-11927. 
Angulo, y lo mismo solía hacer la sirvienta Eugenia Ramírez, que acudía de vez en cuando a bailar al dancing Magallanes sin que ningún familiar la acompañase ${ }^{37}$. Asimismo, en 1921 Milagros Herrera afirmó ir frecuentemente "con amigas” al baile del Palacio de Terpsicore, y lo mismo hacía Teresa Ortega, que acudía con las compañeras del taller de sastrería al Pelikan Kursaal de la calle de Atocha ${ }^{38}$. El caso de la joven peletera Encarnación Rubira resulta especialmente revelador en este sentido: un domingo de abril de 1922, Encarnación salió de su casa para ir al baile que organizaban en Folies Bergère, ubicado a escasos metros de su domicilio, donde había quedado con su novio Juan Rodríguez y con otra pareja de amigos que solían frecuentar como ella aquel dancing de moda. Su madre, enterada por los vecinos del gusto por los bailes que había tomado la muchacha, decidió aquel día perseguirla para comprobar definitivamente esos rumores. Según ella misma afirmó días después ante el juez, Encarnación estuvo en el dancing desde las 15.30 hasta las 19.00 de la tarde, y en todo ese tiempo su madre permaneció esperando fuera del local a que su hija saliera, consciente seguramente de que su presencia allí hubiera estado fuera de lugar ${ }^{39}$.

A diferencia de los bailes de principios de siglo, los de merendero o los de socios, en los que participaban todos los miembros de la familia, a los nuevos bailes comerciales no entraban las madres ni los padres, pues aquel era un lugar y una actividad de entretenimiento dedicada estrictamente a los jóvenes. El público de estos bailes estaba formado, según informan los sumarios y los reportajes de prensa, por chicos y chicas jóvenes, generalmente trabajadores de fábrica o de taller, estudiantes y empleados de los servicios: "horteras y oficinistas engominados", estudiantes "despreocupados de sus libros”, dependientes de comercio, ebanistas, sastres, barberos, albañiles, carniceros, criadas, peleteras, encuadernadoras, vendedoras, taquimecas, cajeras, dependientas “del Madrid-París o de los Rodríguez", sastras o modistas "envenenadas de cine y de novela galante" ${ }^{40}$. Son varios los testimonios de época que atestiguan la costumbre de las jóvenes trabajadoras de acudir a los bailes en los tiempos muertos entre el trabajo y la vuelta a casa que ahora sí, gracias a las victorias en materia de jornada laboral y descanso dominical, podían destinar a sus actividades de ocio. Más allá de las propias declaraciones de las muchachas, novelas de época, reportajes y crónicas sobre la vida de las modistillas o las perfumistas, así como poemas o escritos literarios, pregonan cómo, tras las duras y largas mañanas en el taller, las jóvenes trabajadoras salían a distraerse recuperando "el tiempo perdido en cines, paseos y bailes" 41 .

- Trini, ¿te vienes a bailar?

- Es que tengo que estar en casa a las ocho, para hacer la cena.

- Nos da tiempo, vamos.

- No, no, que no he ido nunca.

- ¿Que no? ¡Anda ésta! ¿No has bailado nunca?

- Alguna vez, en bodas y así. Pero en bailes de verdad, no.

37. AGA, Justicia, leg. (7) 41.4, caja 2856, Top. 43/35.101-35.548; (07) 041.006, caja 44/15472 y (07) 41.010, top: 43/37.606-38.309, caja 7654 .

38. AGA, Justicia, leg. (07) 041.008, caja 44/16080, y (07) 041.008, caja 44/16162.

39. AGA, Justicia, leg. (7) 41.4, caja 2856, Top, 43/35.101-35.548.

40. La Voz, 30-11-1928; Estampa, 31-7-1928; Crónica, 13-7-1930; La Esfera, 11-7-1925.

41. El entrecomillado de un reportaje sobre las modistillas de la revista Estampa, 14-2-1928; otros testimonios en Estampa, 15-1-1929; Rafael LóPEz DE HARO, Flores del dancing, Madrid, Prensa Gráfica, 1924. 
- Pues mejor que mejor. Verás qué bien lo pasamos.

- Que no, chica. ¿No ves que a mí, como casi no sé, no me van a sacar?

- No seas tonta. A mí me conocen todos, y como vienes conmigo te sacarán a ti también.

Todas las tardes, desde aquel día, Trini al salir del trabajo, se iba al salón de baile [...]. A las siete, Trini daba su última puntada, recogía los trapos y salía con sus compañeras. En la acera, varios jóvenes esperaban a las modistas ${ }^{42}$.

Esto solían hacerlo con el consentimiento de sus familias, pero también podían hacerlo sin él. Las nuevas pautas y condiciones de vida que la modernización de la ciudad y de su nuevo mercado de trabajo establecían para estas muchachas de clases populares les otorgaba paralelamente unos márgenes de libertad y autonomía notablemente más extensos y flexibles que en tiempos precedentes. Ello les permitía romper y transgredir algunas de las normas que el discurso social (y algunos de sus padres y madres) asignaban al comportamiento femenino, un discurso social marcadamente fragmentado ya entonces, y que ellas, desde abajo y con sus actitudes cotidianas, estaban contribuyendo a reformular ${ }^{43}$. Las muchachas madrileñas salían por la mañana a trabajar, y sus padres, ocupados en sus respectivos oficios o quehaceres diarios, difícilmente podían controlar dónde iban después de la jornada o si verdaderamente estaban trabajando. El padre de Manuela García, por ejemplo, denunció el rapto de su hija en 1926 al percatarse, por su falta en casa, de que aquella tarde no había acudido como de costumbre a su puesto de taquillera del cine Ideal, sino que se había fugado con un muchacho que había conocido en el mismo cine. María Arana aprovechó que su madre Casilda la envió a hacer un recado una tarde de febrero de 1923 para escaparse con su novio a una casa de citas de la calle del Grafal, donde permaneció con él hasta la mañana siguiente ${ }^{44}$. Así ocurría también en muchas de las causas consultadas, en las que las jóvenes dejaban traslucir en sus declaraciones la amplia independencia de la que disfrutaban para moverse por la ciudad y disfrutar de sus placeres. El tránsito por la calle y el uso del espacio público estaba incorporado a sus rutinas cotidianas, y ahora, en sus idas y venidas al trabajo, o aprovechando las salidas diarias para hacer compras y recados, tenían la oportunidad de hacer uso de los muchos entretenimientos baratos que se encontraban a su paso.

Tener un oficio no solo les daba libertad para moverse a sus anchas, también les reportaba un pequeño capital para poder gastárselo en estos entretenimientos baratos. Como consecuencia de la progresiva mutación del mercado laboral madrileño a raíz de la definitiva consolidación de una economía capitalista de corte industrial y de servicios en la ciudad, tanto las sirvientas, que ya en este periodo empezaban a percibir su

42. Rafael MARTínEz, Trini, novela de una muchacha madrileña, Madrid, Sociedad General Española de Librería, 1936, pp. 17 y 38.

43. Al margen de los trabajos incluidos en la nota 3, a día de hoy no está todavía suficientemente reconocido en la historiografía española especializada el peso que el despliegue y visibilización pública de las nuevas formas de vida de las jóvenes de clases populares urbanas tuvo en la configuración de los nuevos modelos de feminidad moderna que empezaron a circular en el discurso público en los años de entreguerras. Una crítica más desarrollada sobre esta cuestión en Cristina DE PEDRO y Rubén PALLOL, "Chicas modernas y de barrio. La modernidad femenina alternativa de las jóvenes de clases populares urbanas en el periodo de entreguerras”, Feminismo(s), 37 (2021), pp. 187-210 (https://doi.org/10.14198/fem.2021.37.08).

44. AGA, Justicia, leg. (07) 041.003, caja: 1673, top. 43/66.101-66.704, y (07) 041.008, Caja 44/16103. 
remuneración en metálico y no siempre "con manutención" 45 , como el resto de trabajadoras de fábrica o taller, disponían de sueldos monetarizados que podían destinar, al menos parcialmente, a financiar sus actividades de ocio ${ }^{46}$. Es cierto que gran parte de esos salarios debían ser entregados a las familias, que necesitaban de ellos para poder subsistir. Sin embargo, vista la frecuencia con la que las jóvenes salían por los locales de ocio comercializado, parece plausible pensar que sus mayores les permitían conservar parte de su jornal para financiar sus entretenimientos. Encarnación Rubira, por ejemplo, llevaba 15 pesetas consigo el día que acudió al dancing Folies Bergère con su novio Juan y con la otra pareja de amigos, y con ellas pretendía financiar la habitación en la casa de citas de la calle del Barco a la que acudieron los cuatro juntos una vez terminado el baile ${ }^{47}$.

Estudios similares sobre otras ciudades en el contexto de entreguerras revelan que el hecho de poseer un trabajo y saberse imprescindibles para el mantenimiento de los hogares podía otorgar a estas jóvenes el derecho a demandar o exigir una contrapartida, que muchas veces significaba poder disponer de algo de metálico para pagarse una entrada al cine o al baile de moda. Esto era especialmente habitual en el seno de las familias monoparentales, como la de Dolores, donde la falta de una figura paterna (situación bastante habitual en los casos consultados) le otorgaba a la hija trabajadora más capacidad y poder de negociación en las discusiones sobre el reparto de presupuesto familiar y sobre la concreción de los horarios de salida ${ }^{48}$. Al fin y al cabo, el presupuesto semanal dependía en gran parte de ellas, y muchas veces las madres se veían obligadas a ceder. Había algunas que incluso se negaban frontalmente o se buscaban artimañas para no entregar su salario en casa, como la joven María de la Luz, que el 25 de diciembre de 1915 se escapó de su domicilio tras haber tenido un disgusto con sus padres porque "aquella no les entregaba el salario que ganaba por su oficio de modista, contestando siempre que lo había entregado a una persona y que ya lo entregaría"49. Además, aunque el remanente que les quedara de sus salarios no fuera muy abundante, el bajo coste de los nuevos bailes comerciales permitía a estas jóvenes hacer uso de ellos sin grandes sacrificios económicos. Es más, cuando no era así, cuando las muchachas no tenían con qué pagárselos, se buscaban las maneras para ser invitadas por sus novios o sus ligues pasajeros, empleando distintas estrategias que les permitían no renunciar a las nuevas diversiones que les ofrecía la urbe y que generaban

45 Sobre la transformación del oficio de empleada doméstica, Santiago DE MiguEL, Borja CARBALLO y Cristina DE PEDRO, "La evolución del servicio doméstico en el mercado laboral madrileño”, Revista de Demografía Histórica, 34, 1 (2016), pp. 63-100.

46. Sobre los nuevos empleos en fábricas y talleres de las jóvenes de clases populares madrileñas, Paloma CANDELA, "El trabajo doblemente invisible. Mujeres en la industria madrileña del primer tercio del siglo XX”, Historia Social, 45 (2003), pp. 139-159; Rubén PALlOL, "Trabajadoras en una economía en transformación. La participación laboral de las madrileñas en el primer tercio del siglo XX”, Sociología del trabajo, 89 (2017), pp. 53-74; Pilar DíAz, "Del taller de costura a la fábrica. El trabajo de las mujeres en la confección textil madrileña”, Cuadernos de Historia Contemporánea, 21 (1999), pp. 279-293.

47. AGA, Justicia, leg. (7) 41.4, caja 2856, top: 43/35.101-35.548.

48. Elisabeth A. Clement, Love for Sale: Courting, Treating, and Prostitution in New York City, 19001945, Chapel Hill, The University of North Carolina Press, 2006, pp. 13-44; Ruth M. ALEXANDER, The Girl Problem: Female Sexual Delinquency in New York, 1900-1930, Ithaca, Cornell University Press, 1998.

49. AGA, Justicia, leg. (07) 041.003, caja 1560, top. 43/66.101-66.705. 
entre ellas auténtica fascinación ${ }^{50}$. Y es que esta era la lógica de los nuevos dancings: atraer a las muchachas con sus exiguos precios y su variada y excitante programación para que acudieran allí a divertirse junto a otros y otras jóvenes de la ciudad.

\section{El nuevo flirt del dancing}

Los nuevos bailes comerciales actuaron, así, como centros esenciales de ocio y encuentro mixto al margen de las familias para los jóvenes de los barrios populares de Madrid. Como vemos, se trataba de espacios sociales en los que se animaba y legitimaba la presencia de las jóvenes trabajadoras y donde se gestaba día a día, en cada una de estas salidas de ocio de los y las muchachas madrileñas, la nueva naturaleza heterosocial de la cultura moderna del entretenimiento. La propia lógica de funcionamiento de estos bailes exigía el encuentro y el contacto entre chicos y chicas: aunque se fuera solo, allí se iba a bailar en pareja, y encontrar una compañera para el baile era la misión de todo joven trabajador que atravesara la puerta de alguno de los dancings de la ciudad. El hecho de que estos bailes fueran terreno exclusivo de la juventud los convertía en lugares idóneos, no solo para el encuentro heterosocial, sino también para el contacto y la interacción amorosa y sexual. Por ello, estas salas de baile fueron piezas clave en la creación de nuevos valores compartidos en torno a la sexualidad, el noviazgo y las relaciones de género, pues por su propio funcionamiento obligaban a gestionar situaciones que interpelaban a cuestiones como la intimidad, la sexualidad y la respetabilidad. La articulación de nuevas ideas sobre el sexo y las relaciones eróticas entre hombres y mujeres en los años de entreguerras no solo procedía, pues, de las adelantadas deliberaciones de algunos médicos o de los programas y aspiraciones de los incipientes movimientos de reforma sexual, sino que eran resultado también, y quizá antes, de la propia gestación de nuevas formas de vida y rituales de interactuación heterosocial aparecidas al calor de la experiencia urbana ${ }^{51}$.

En primer lugar, las propias danzas modernas que se bailaban sobre la pista, decían, eran a su vez causa e indicación evidente del actual "desquite de las costumbres" ${ }^{2}$. Los anuncios de orquestas americanas, de jazz o de tango que aparecen

50. Algunas de las jóvenes de los sumarios, como Juliana Pancorbo o Petra Moreno, desplegaron estrategias y prácticas conocidas como treating en la bibliografía anglosajona, que consistía en el intercambio de favores sexuales a cambio de invitaciones al cine o al baile, o consumiciones en bares y cafés, pero nunca a cambio de pago en metálico, pues eso era lo que las diferenciaba de las prostitutas (AGA, Justicia, leg. (07) 41.010, top: 43/37.606-38.309, caja: 7654, y (07) 41.010, top. 43/37.606-38.309, caja 7650). Un excelente trabajo sobre esta práctica en CLEMENT, Love for Sale, pp. 45-75.

51. Sobre el desarrollo de movimientos de reforma sexual en España y la transformación de los ideales de género asociados a la sexualidad en el primer tercio del siglo XX cabe destacar, entre la bibliografía disponible: Nerea ARESTI, Médicos, donjuanes y mujeres modernas. Los ideales de feminidad y masculinidad en el primer tercio del siglo $X X$, Bilbao, Universidad del País Vasco, 2001; ídem, "La nueva mujer sexual y el varón domesticado. El movimiento liberal para la reforma de la sexualidad”, Arenal, 9-1 (2002), pp. 125-150; ídem, "Be Cautious, Not Chaste! Gender Ideals and Sexuality (19201936)”, en María Luz Esteban y Mila AMURri, Feminist Challenges in the Social Sciences. Gender Studies in the Basque Country, Reno, Center for Basque Estudies, 2010, pp. 71-84; Alison SINCLAIR, Sex and Society in Early Twentieth-century Spain: Hildegart Rodríguez and the World League for Sexual Reform, Cardiff, University of Wales, 2007; Helena ANDRÉs, "Maternidad consciente y voluntaria. Eugenesia y emancipación femenina en el anarquismo español, 1900-1939”, tesis doctoral, Universidad de Zaragoza, 2016; Rafael Huertas y Enric Novella, “Sexo y Modernidad en la España de la Segunda República. Los discursos de la ciencia”, Arbor, 189, 764 (2013).

52. La Esfera, 15-11-1930. 
en las carteleras de las salas de baile evidencian, junto a los reportajes de prensa gráfica, la marcada implantación de las músicas y bailes extranjeros en estos dancings del Madrid de entreguerras. Un artículo de Nuevo Mundo de octubre de 1926 señalaba, por ejemplo, que el charlestón había arraigado en Madrid en el invierto de 1925 y que sus "primeras exhibiciones" habían tomado cuerpo, de hecho, en los nuevos "dancings democráticos de las modistas". Pero antes que él, matizaba, otros tipos de baile americano, "primero el fox" y "más tarde el shimmy", habían roto ya la "serenidad de los bailes tradicionales" ${ }^{3}$. El "Madrid frívolo de la posguerra", insistían unos y otros, había acabado con los ritmos y cadencias pausadas, nobles y lentas del chotis, del vals o de la habanera, bailes ya pasados de moda, que habían perdido fuelle frente al arrastre del apasionado tango argentino y las frenéticas danzas americanas ${ }^{54}$.

El tango, para entonces, era ya "huésped continuo" de Madrid. Sus melodías estaban ya "en boca de la aristócrata y en los labios de la modista; en la orquesta de gran hotel y en la pianola de bar”. Madrid vivía, desde hacía tiempo "la hora del tango" y era algo "tan característico del Madrid de la posguerra como la nueva indumentaria femenina y las melenitas de nuestras garçonnes" 55. Aunque su "momento literario", afirmaban, ya había pasado, "quedó incorporada a la vida frívola de Madrid su música” y sus compases se escuchaban desde que el tango sonó en la ciudad por primera vez. "No se concibe un dancing sin su orquesta de tangos, que alterna con la orquesta americana de jibis y de blues”56. En efecto, según informan las carteleras, los pases de tango compartían pista con los fox, los charleston o los black-bottom en las salas de baile de Madrid, nuevas danzas "estridentes”, “epilépticas”, “descoyuntadas”, que "contorsionaban ritmos y actitudes en una febril exaltación de la pirueta” y en las que "las piernas de la mujer incansablemente saltan, giran, se quiebran, avanzan, retroceden, se buscan, se esquivan" ${ }^{27}$. Algo parecido a esto debía bailarse en el Folies Bergère en 1926 (ya llamado para entonces El As) a juzgar por la queja que los vecinos de la calle enviaron al periódico $L a \mathrm{Voz}^{58}$ :

Unos vecinos que no duermen. Los vecinos de la calle de Andrés Borrego, números 12 y 14, nos escriben: "Se nos hace imposible la vida por los escándalos que diariamente y a altas horas de la madrugada se promueven en el baile que hay establecido en la casa contigua de la referida calle, pues, no contentos con el ruido que ya de por sí produce el baile y su estrepitoso jazz-band, hace ya unas cuantas noches que las cincuenta o sesenta personas que allí se reúnen se dedican a jugar al corro, dando patadas en el entarimado de madera del salón y chillando desaforadamente, expansiones que a esas horas impiden dormir a ninguno de los vecinos de

53. Nuevo Mundo, 15-10-1926.

54. Crónica, 3-5-1931; La Esfera, 11-7-1935 y 15-11-1930.

55. Mundo Gráfico, 22-6-1927.

56. Nuevo Mundo, 20-1-1928.

57. Nuevo Mundo, 15-10-1926 y 7-3-1924; La Esfera, 15-11-1930; Crónica, 3-5-1931; Estampa, 17-61930.

58. Los periódicos de la época recuperan múltiples quejas y protestas similares a esta, en las que se refleja cómo la gestación de las nuevas dinámicas y ritmos de ocio mercantilizado en los años de entreguerras no estuvo exenta de conflicto: Rubén PALLOL, "Conquistar, democratizar y domesticar la noche en la ciudad moderna. Modernización, desigualdad y conflicto en Madrid a comienzos del siglo XX”, Registros, 13, 1 (2017), pp. 149-195; ídem, "La lucha por la respetabilidad en el espacio urbano. Madrid, 1900-1930. Clase media, ocio popular y control del espacio público”, en Santiago CASTILlO y Jorge URíA, Sociedades y culturas: IX Congreso de Historia Social. Treinta años de la Asociación de Historia social, Madrid, Asociación de Historia Social, 2019, pp. 427-446. 
esta casa, la mayoría oficinistas o empleados que han de madrugar para ir a su ocupación. ¿o habría medio de que las autoridades pusieran coto a esto?”59.

Los nuevos bailes americanos de la posguerra eran, para algunos, manifestación del triunfo de lo negro en Madrid. Y con ello no se referían, o no solo, a las y los negros que, según la revista Mundo Gráfico, habitaban y trabajaban en la ciudad como porteros de hotel, empleados de guardarropa, chóferes de taxis, criadas, y sobre todo directores y músicos de orquesta de jazz, y danzarinas y artistas de variedades que, como Josephine Baker, conquistaban los teatros y cabarets de "gran postín" ${ }^{60}$. Cuando hablaban de "la fiebre negra" que había inundado "las calles de la ciudad" hacían referencia al primitivismo de los nuevos bailes que inspiraba la jazzband, asociando el "ejercicio violento y grotesco" de los bailes modernos a las danzas "roncas y arcaicas" de los negros de África, "epilepsias salvajes de los ritos ancestrales", "imitación de los movimientos de los animales inferiores". Para algunos, los bailes americanos que arrancaban al son de una orquesta de negros eran una señal de victoria de la "selva lejana sobre la ciudad moderna”, eran síntoma de la degeneración, de la regresión del ser humano a su estado salvaje e instintivo ${ }^{61}$.

La reacción, común a la surgida en otros países del entorno, no venía solo por el rechazo que entre ciertos sectores generaba la penetración de músicas y productos culturales foráneos en la castiza capital española, provocando, según decían, la decadencia del teatro de buen gusto y los géneros musicales típicamente nacionales ${ }^{62}$. El rechazo venía también por la nueva moralidad y sentimentalidad que estas danzas modernas llevaban adscritas, por las nuevas conductas y formas de interacción sensual y erótica que estas inspiraban y que asemejaban cada vez más a Madrid, al menos en lo que concernía a las prácticas y costumbres de ocio de su juventud popular, a los modos y hábitos culturales de otras capitales del mundo. El tango, por un lado, baile engendrado en los burdeles de Buenos Aires, incorporaba altas dosis de sensualidad y estrechamiento físico a la interacción dancística, pese a que algunos de sus pasos más objetables habían sido ya depurados en su traslado a Europa desde los bajos fondos de la ciudad bonaerense ${ }^{63}$. "En cuanto al tango argentino", decía la revista Estampa, "no hay para qué hablar siquiera de sus efectos. Todo un Papa -el docto Pío X-se dedicó a condenarlo, y eso que, seguramente, ni siquiera llegaría a verlo bailar" ${ }^{64}$. Por otro lado, los alocados ritmos americanos eran, junto a las nuevas modas sueltas y desencorsetadas, otra de las vías de liberación del cuerpo femenino, que se dejaba llevar ahora por las rápidas y bruscas oscilaciones del charlestón, "muy especialmente de esa parte en donde la espalda pierde su honesto nombre”. Además, al fox, al shimmy y al

59. La Voz, 28-5-1926.

60. Mundo Gráfico, 23-10-1935.

61. Los entrecomillados en La Esfera, 15-11-1930; Nuevo Mundo, 5-2- y 28-11-1930. Un estudio sobre el primitivismo asociado a los bailes de la artista Josephine Baker en Nancy NENNO, "Feminity, the Primitive and the Modern Urban Space. Josephine Baker in Berlin", en Katharina Von ANKUM, Women in the Metropolis. Gender and Modernity in Weimar Culture, Londres, University of California Press, 1997, pp. 145-161 (https://doi.org/10.1525/9780520917606-008).

62. Carlos SERRANo y Serge SALAÜN, Los felices años 20. España, crisis y modernidad, Madrid, Marcial Pons, 2001, pp. 187-212; Serge SALAÜN, "Política y moral en el teatro comercial a principios de siglo", en ídem y Marie Franco, Les Spectacles en Espagne (1875-1936), París, Presses Sorbonne Nouvelle, 2011, pp. 65-85.

63. WALKOWITZ, Night's Out, p. 191.

64. Estampa, 17-6-1930.

Rubrica Contemporanea, vol. X, n. 19, 2021 
black-bottom, señalaban, les correspondía una sentimentalidad que nada tenía que ver con la ceremoniosidad y respetabilidad de los bailes pasados: el dinamismo y la rapidez de la época "se ha infiltrado en todo", incluso "en el sentimentalismo y la atracción amorosa” ${ }^{65}$. Estas percepciones quizá expliquen algunos de los ataques que ciertos vecinos de Madrid dirigían contra las muchachas que acudían a estos bailes:

Contra un baile. Señor D. José Rocamora. Muy señor nuestro: en nombre de la moralidad y la salud pública rogamos a usted dé cabida en las columnas de su periódico y en el lugar correspondiente a la siguiente queja: Todos los vecinos de la calle de Tetuán estamos escandalizados con lo que ocurre en el baile que existe en el núm. 31 de dicha calle, llamado “La Gruta”. Es un centro de corrupción, donde no asisten más que locas jovenzuelas que allí pierden la noción de la vergüenza, que con sus desplantes y escándalos a la entrada y a la salida a la una y pico de la madrugada tienen escandalizado al honrado vecindario ${ }^{66}$.

Así, aunque controlados y pautados por los propios pasos de baile y por el correspondiente encargado o bastonero del local, los jóvenes que acudían a los dancings madrileños se lanzaban a bailar las modernas danzas sobre la pista, agitando y estrechando fervorosamente sus cuerpos, según, al son del último fox o el último tango de Gámez o de Gardel ${ }^{67}$. También bailaban pasodobles y chotis, que alternaban con los nuevos bailes en las partituras de las orquestas y bandas. En Madrid bailaban hasta los desafortunados que, por poco agraciados o por "cazos" 68 , no hallaban pareja que los acompañara, a quienes el nuevo servicio de "chicas-taxi” que se instauró en algunas salas ya en los años treinta, les servía como solución. El Taxi Apolo, en la calle de la Salud $\mathrm{n}^{\circ}$ 18, y el Satán, en la de Atocha $\mathrm{n}^{\circ}$ 60, anunciaban en sus carteleras estos bailes con "señoritas-taxi”, una moda y un oficio que fue exportado desde Estados Unidos y que en los años previos a la guerra terminó por arraigar en los locales de Madrid ${ }^{69}$.

Las chicas taxi eran muchachas que contrataban los dancings para bailar con los desparejados. Estas se colocaban en el situado, una zona con sillas o bancos alojados en un rincón de la sala donde esperaban a ser elegidas por alguno de los asistentes. Aquellos que lo desearan podían comprar tickets (5 tickets a 1,50, decía la revista Crónica en 1933), y gastar cada uno de ellos en un pase con una taxi-girl. Una vez terminado el baile, la chica recogía el ticket y al final de la tarde pasaba por caja con todos los que hubiera recopilado, que rondaban los "cuarenta y cincuenta", ganando un total de "15 céntimos por ticket”. Según la revista Crónica (y así lo confirman los estudios abajo señalados sobre las dance partners de otras ciudades), las chicas-taxi eran habitualmente jóvenes trabajadoras que acudían por las tardes a las salas de baile para ganarse un sobresueldo, alrededor de unas "5 o 6 pesetas diarias" que obtenían "al tiempo que se divierten bailando”. Su fama nada tenía que ver con las de otras chicas

\section{La Esfera, 15-11-1930.}

66. El Heraldo de Madrid, 24-4-1924.

67. Sobre la popularidad de los tangos de Carlos Gardel y de Celia Gámez en los dancings populares de Madrid, Nuevo Mundo, 20-1-1928.

68. “Cazo” era la forma en la que se denominaba coloquialmente a los que no estaban muy formados en el arte de la danza. Así los describía una modista ficticia en un reportaje de La Voz de 30-11-1930: “¿No sabe usted lo que es un cazo? Un cazo es... una marmota [...] esas personas que se empeñan en bailar, olvidándose de que han nacido para apisonadoras”. En los mismos términos se refería Trini a este tipo de muchachos en la novela de MARTínEZ, Trini, p. 19.

69. Existen varios trabajos que abordan el fenómeno de las taxi-girls en distintas ciudades de Europa y Estados Unidos: Angela I. FRITZ, “'The Woman who Danced for a Living'. Exploring Taxi Dancers Childhood in Chicago's Polish American Communities, 1920-1926”, Journal of the History of Sexuality, 23 (2014), pp. 247-272 (https://doi.org/10.7560/JHS23205). Véase además nota 2. 
que "vendían” su cuerpo y su compañía a cambio de propinas, las tanguistas, que eran contratadas en los bares y cabarets para alternar con los clientes y animarlos a beber. Las señoritas-taxi tenían prohibido "terminantemente" alternar con los muchachos tras el baile y sus movimientos estaban estrictamente controlados, decían, por un empleado del local, al que en algunas novelas de época llamaban jocosamente "el Ojo Alerta"70.

Pero más allá de la propia danza, del contacto y el roce de cuerpos que esta podía generar entre las parejas de aficionados, las salas de baile eran lugares donde se gestaba el flirt, apelativo que usaban en la época para hacer referencia al flirteo y coqueteo que surgía de la interacción heterosocial en estos locales, y que era resultado del uso creativo que los jóvenes hacían de ellos. En efecto, al dancing se iba a bailar y a divertirse, pues para eso se habían concebido estos locales, pero los muchachos y muchachas aprovechaban la intimidad y cercanía con el sexo opuesto que ofrecían aquellos lugares para cruzar miradas, acercarse, hablarse y tocarse. Para ligar y encontrar pareja, en definitiva, fuera esta del tipo que fuera. La revista Nuevo Mundo hacía un repaso de los tipos de parejas que podían encontrarse en los bailes en un artículo publicado el 30 de agosto de 1929: de la "pareja que viene a divertirse", que "goza de la alegría del momento"; de la "pareja romántica" formada por dos novios o dos que "están a punto de serlo", que "bailan muy junto" y hablan "muy quedito y al oído"; de la "pareja sensual" que "ha ido al baile a abrazarse, y lo hace a conciencia, amparada en la más absoluta impunidad"; de la pareja de los "virtuosos del baile” o de las "parejas incompletas", en las que "él suele ser un sensual y ella una que va a divertirse, o él un virtuoso, y ella una romántica que ha ido con la ilusión de encontrar un amor"71. En esta misma cualidad de los bailes modernos como "incubadores" de amoríos y noviazgos insistía la revista Crónica ya en julio de 1936: “A estos bailes de nuestra época democrática, en los que se puede hallar pareja sin necesidad de que sea presentada [...] vosotras, muchachas de hoy bailáis con este muchacho a quien no conocíais ayer e ignoráis lo que podrá ser para vosotras mañana”72.

Los nuevos bailes eran lugares de encuentro y flirteo entre desconocidos, en los que se fraguaban romances y relaciones de distinto tipo sin control ni vigilancia por parte de las familias. Más allá de la manifiesta libertad de actuación que esto suponía para los muchachos a la hora de socializar e interaccionar entre ellos, la aparición de los dancings contribuía a acelerar transformaciones de mayor calado que atentaban de raíz contra las estrategias de organización familiar y matrimonial que habían predominado en contextos premodernos. Por un lado, al erigirse como espacios exclusivos de la juventud, en los que se gestaban vínculos y uniones amorosas entre chicos y chicas que no tenían por qué conocerse previamente, los nuevos bailes fomentaban la proliferación de noviazgos fraguados sin la intermediación de los padres, quienes empezaban a tener

70. Una descripción muy completa de cómo funcionaba el servicio de las taxi-girls en Madrid en Crónica, 26-3-1933, y en MARTíNEZ, Trini, pp. 70-74.

71. Nuevo Mundo, 30-8-1929.

72. Crónica, 19-7-1936. 
cada vez menos que decir en la elección de la pareja de sus hijos ${ }^{73}$. No solo la prensa documenta este fenómeno, los propios sumarios judiciales dan igualmente cuenta de él: igual que ocurrió con Dolores y Matías, Encarnación Rubira había conocido a Juan Rodríguez en un baile de la Bombilla, donde se gestó un noviazgo que duró al menos seis meses y que estuvo salpicado de salidas constantes a cines y bailes de la ciudad como el Folies Bergère. Lo mismo ocurrió en el caso de Dolores Lozano y Antonio Fernández, que se habían hecho novios después de conocerse en un baile de los Cuatro Caminos llamado Buenos Aires ${ }^{74}$.

Además de favorecer la formalización de noviazgos sin el concurso de los familiares, los dancings daban lugar asimismo a la configuración de otros amoríos menos duraderos o formales, como el de la modista Josefa García con el estudiante Claudio Pardo, iniciado en un baile del Retiro, o como el de la joven Mercedes Domau y aquel muchacho desconocido de Vallecas al que vio por primera en el baile El Angulo $^{75}$. Los bailes eran, pues, auténticas incubadoras de noviazgos formales, pero también de romances pasajeros. La revista Estampa se refería a estos idilios con el calificativo de "novios exprés", y los definía como aquellos amoríos que duraban "una tarde, o dos días, o una sesión de cinematógrafo" ${ }^{76}$. La generalización de estas uniones pasajeras implicaba igualmente un cambio cultural de importante trascendencia, pues diversificaba los formatos de relación sentimental y erótica disponibles e imaginables para estos jóvenes, a la par que cuestionaba la inmutabilidad del vínculo entre noviazgo y matrimonio ${ }^{77}$. Como indicaba la revista Estampa en uno de sus reportajes sobre un baile "de sirvientas":

- La chica de baile -continúa diciéndome el camarero- no se hace antigua en ningún salón. No

le gusta que la conozcan mucho. Hoy viene aquí, mañana va a otro sitio y pasado a otro.

- ¿Así que la clientela no es fija?

- No

- ¿Vienen muchas mujeres solas?

- Muchas. Solo que después se van acompañadas.

- ¿Salen muchos noviazgos de estos bailes?

- Muchos; pero suelen ser nublados de verano, que pasan pronto. De los bailes salen pocas bodas"78.

73. Pilar MuÑOz explica a este respecto que, ya a finales del siglo XIX, era poco común que los padres organizaran matrimonios sin contar con los sentimientos y opiniones de los hijos, pero que, pese a todo, estos aún jugaban un papel de primer orden en la elección de su futura pareja (Sangre, amor e interés. La familia en la España de la Restauración, Madrid, Marcial Pons, 2001, pp. 67-80). Sin embargo, a juzgar por los conflictos familiares que sacan a la luz algunos sumarios judiciales incoados en el Madrid de los años 1920 y 1930, lo que parece observarse es que, en contextos urbanos, para algunas de estas hijas e hijos de las clases populares, la connivencia de los padres ya no se consideraba imprescindible para la formalización de un noviazgo (Rubén PALLOL y Cristina DE PEDRO, "Rapto de novias, honra de doncellas y honor familiar. Discursos y conflictos en torno a la crisis del orden de los sexos en la sociedad urbana de comienzos del siglo XX”, Clío y crimen. Revista del Centro de Historia del Crimen de Durango, 13 (2016), pp. 289-306; Cristina DE PEDRO, “Amor, emociones y masculinidad en el Madrid de entreguerras”, Arenal, 4, 2 (2017), pp. 539-557).

74. AGA, Justicia, leg. (7) 41.4, caja 2856, top: 43/35.101-35.548; (07) 041.002, caja: 0867, top. 43/31.702-33.207.

75. AGA Justicia. leg. (07) 041.008, caja 44/16123 y 8289 (Diligencias).

76. Estampa, 8-7-1930.

77. Sobre la estricta reglamentación del noviazgo en la España de la Restauración, MuÑoz, Sangre, amor e interés, pp. 81-129.

78. Estampa, 16 de febrero de 1935. 
Ser una chica de baile podía atesorar distintas consideraciones en el Madrid de los años treinta. Para algunas familias, como la de Encarnación Rubira, esto constituía un peligro para la honra y honestidad de las muchachas, pues sabían que al baile no se acudía solo para bailar. Su madre lo dejó bien claro cuando declaró ante el juez que había decidido vigilar las salidas de su hija, pues a ella "no le parecen bien tales diversiones". En los mismos términos lo entendían los padres de María de la Luz, quienes acusaban a su hija de haber contribuido a "deshonrar" a la hermana pequeña de la familia (recientemente embarazada) por llevarla consigo a bailar al dancing Ideal Polistilo $^{79}$. Efectivamente, como vimos con Dolores y Matías, ir al baile era sinónimo de flirteo e incluso podía ser una antesala para el contacto sexual, pero en ocasiones algunos padres no distinguían entre los distintos usos sexuales o amorosos que los jóvenes podían hacer de aquellos locales, y pasaban todos los comportamientos por el mismo rasero.

Por el contrario, parece que los jóvenes madrileños no solo eran conocedores de los importantes matices que existían entre los distintos tipos de interacción heterosocial que podían darse en estos bailes, sino que también establecían grandes diferencias en cuanto a la consideración que para ellos tenían unos y otros. Ir al dancing en soltería, aunque ello pudiera entenderse per se como una confirmación de disponibilidad sexual, no parecía suponer un problema para la moralidad de las jóvenes, como tampoco lo parecía el hecho de conocer al novio en este tipo de locales, incluso aunque ello trajera consigo un posterior encuentro sexual. No pareció suponerlo para Encarnación Rubira cuando tuvo que declarar ante el Juez y afirmó abiertamente que aquella tarde de abril de 1922, cuando salió del Folies Bergère junto con su novio, ambos se dirigían a una casa de citas de la calle del Barco $\mathrm{n}^{0} 3^{80}$. Tampoco para la joven Dolores Lozano, quien reconoció que después de un mes de noviazgo con un muchacho al que había conocido en el baile Buenos Aires, se entregó a él en un callejón entre Bravo Murillo y Santa Engracia $^{81}$. A juzgar por los testimonios extraídos de la documentación, algunas jóvenes de los barrios populares del Madrid de entreguerras deseaban y consideraban legítimo el intercambio sexual en las relaciones de noviazgo, especialmente cuando se trataba de un noviazgo formal con visos a formalizarse en un matrimonio, aunque esto no era siempre un requisito indispensable ${ }^{82}$.

Sin embargo, la concepción que estos dancings tenían entre la juventud como lugares para el contacto y la interacción sensual con el otro sexo hacía que el hecho de ir al baile sola o con amigas teniendo novio formal estuviera mal visto por algunos muchachos. Así, por ejemplo, el joven barnizador de 23 años Timoteo García alegó el 15 de marzo de 1930 que había roto su noviazgo de un año y medio con su novia de 18 años Hortensia Blanco “devolviéndola los retratos y las cartas que de ella tenía porque no le gustaba la afición que tenía la Hortensia al baile y a lo corta que vestía” ${ }^{83}$. En los mismos términos se expresó el novillero de 20 años Mariano Miguel Fernández cuando le explicó al Juez de qué conocía a la sirvienta Petra Moreno: “Que conoce a Petra, con

79. AGA, Justicia, leg. (7) 41.4, caja 2856, top: 43/35.101-35.548; (07) 041.003, caja 1560, top. 43/66.101-66.705.

80. AGA, Justicia, leg. (7) 41.4, caja 2856, top: 43/35.101-35.548.

81. Ibídem, (07) 041.008, caja 44/16153 y (07) 041.002, caja 0867, top. 43/31.702-33.207.

82 Esta cuestión se aborda con más detalle en PALLOL y DE PEDRO, "Rapto de novias, honra de doncellas y honor familiar”.

83. AGA, Justicia, leg. (07) 041.008, caja 44/16193. 
la que tuvo relaciones amorosas durante un mes o mes y medio. Que como vio que frecuentaba todos los bailes y que tan pronto andaba con unos como con otros optó por no volver a verla, dando por terminadas las relaciones" ${ }^{84}$. Una percepción similar sobre los bailes se extrae de una carta que el joven ebanista José Golmar le envió a su novia Juana Villanueva desde Murcia el 18 de octubre de 1924:

Estoy deseando de berte [sic] a mi presencia me dirás cuando bienes [sic]. Tengo mucho que contarte y deseo que bengas $[\mathrm{sic}]$ pronto. Me dices que no fuiste al baile por no faltarme. Te doy las gracias ${ }^{85}$.

Acudir a estos dancings teniendo un novio más o menos serio podía considerarse, pues, una falta, a no ser que se fuera con él, como hicieron Dolores y Encarnación. Pero, como vemos, no todas las novias respetaban esa norma, y acudían a los bailes a pesar del disgusto que eso les generaba a los muchachos, a sabiendas de que su comportamiento podía poner en riesgo las relaciones amorosas. Para algunas de ellas, quizá el deseo de conservar el novio pesara menos que el de renunciar a las nuevas diversiones que ofrecía la ciudad. Otras tal vez no pretendían siquiera que esos amoríos pasaran a mayores, pues lo que ellas querían era pasárselo bien con unos y con otros, sin grandes compromisos ni preocupaciones. La documentación judicial recoge casos de algunas jóvenes que efectivamente no parecían tener especial interés en mantener una relación formal o duradera, y recopilaban novios o amigos con los que iban a cines y a bailes y se acostaban a veces en los descampados y casas de citas. Eugenia Ramírez, por ejemplo, había sido “deshonrada” en julio de 1929 por un muchacho panadero llamado Manuel Fernández, y meses después, en diciembre, fue encontrada en una casa de citas de la calle del Abel con otro joven albañil llamado Cándido Couto, a quien había conocido en un baile de la calle Magallanes. Al ser preguntado por el juez, Cándido dijo que Eugenia le había confesado haber tenido ya relaciones sexuales con un antiguo novio, y que por tanto "no tuvo inconveniente en tener contacto carnal con la misma en varias ocasiones sin haberle puesto ninguna vez precio al acto, sino únicamente por la simpatía hacia el declarante”. Eugenia confirmó la versión de Cándido, afirmando que "por su deseo" había entrado en la casa de citas de la calle del Abel n 9 "con su amigo, mejor dicho, novio”, al cual había conocido en el baile Magallanes. De hecho, ella misma dijo, cuando la dueña de la casa le preguntó al entrar que no era la primera vez que mantenía relaciones sexuales, pues "lo había hecho ya muchas veces, algunas en casas de recibir y otras en el campo" 86 .

De las declaraciones puede deducirse, no obstante, que este tipo de conductas sí solían estar sancionadas entre la juventud. A Eugenia, de hecho, la había denunciado un antiguo novio con objeto de demostrar "que la referida hace mala vida", por realizar "actos carnales con varios hombres”. Asimismo, la joven sirvienta Jovita Beloy, al ser preguntada en 1929 por el comportamiento de su vecina Juliana Pancorbo, quien había sido hallada por dos agentes de policía en una casa de citas de la calle del Espíritu Santo $n^{0}$ 33, realizó una valoración parecida de su comportamiento. La muchacha afirmó que "Juliana, desde hace un tiempo, hace vida muy irregular, pues ha estado trabajando como camarera” y “cada día tiene un novio”. Además, la muchacha, decía, "había tenido trato íntimo con varios individuos” y "tan pronto anda por unos sitios como por

84. AGA, Justicia, leg. (07) 41.010, top: 43/37.606-38.309, caja 7650.

85. AGA, Justicia, leg. (07) 041.008, caja 44/16150.

86. AGA, Justicia, leg. (07) 41.010, top: 43/37.606-38.309, Caja: 7654.

Rubrica Contemporanea, vol. X, n. 19, 2021 


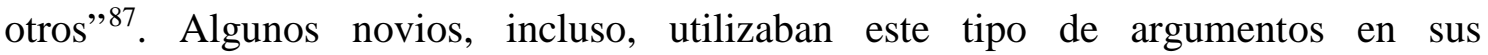
declaraciones para desvirtuar a las chicas a ojos del juez y así lograr quedar impunes ante las acusaciones de estupro o violación: el mismo Matías Carrascosa, cuando fue denunciado por haber engañado a Dolores para conseguir acostarse con ella, acusó a la joven de estar ya deshonrada y de haber tenido "trato" con varios hombres antes de estar con él. Si era cierto no lo sabemos, pues ella lo negó todo y él se mantuvo firme en su declaración, pero lo que parece claro es que ni para uno ni para la otra, ni para el juez que debía determinar la resolución, esto era visto como un comportamiento legítimo para una joven que se pretendiera respetable.

En los bailes, así como en los cines o en cualquiera de los entretenimientos baratos que la ciudad había puesto al servicio de la juventud popular madrileña en el periodo de entreguerras, podían encontrarse, pues, diversos tipos de parejas y una variada gama de actitudes femeninas en lo que respecta a su comportamiento sexual. Los propios bailes actuaron como espacios de renegociación de conductas y valores comunes en torno al sexo y la interacción heterosocial, en los que se expresaron nuevas actitudes y se esgrimieron diversas apreciaciones al respecto de ellas. Aunque parecían existir algunos consensos, las jóvenes se movían en un terreno resbaladizo, pues actuaban dentro de un contexto generalizado de cambios convulsos en el que, sobre todo entre la juventud, los límites de lo respetable o tolerable en lo referido a la interacción entre los sexos eran cada vez más inestables y difusos. Como han puesto de manifiesto distintas investigaciones, las consideraciones sociales acerca de cómo debían comportarse hombres y mujeres en la intimidad se encontraban entonces, en los años de entreguerras, en pleno proceso de renegociación. La contribución que estas jóvenes hicieron al debate desde abajo, al mostrarse públicamente flirteando en los dancings o al protagonizar sumarios judiciales a raíz de su comportamiento sexual es aún, sin embargo, un asunto pendiente de incorporar a la reflexión.

\section{Conclusiones}

La historia que protagonizaron en 1921 Dolores Domínguez y Matías Carrascosa constituye un ejemplo muy ilustrativo del tipo de prácticas de ocio que la juventud de extracción popular podía llevar a cabo en el Madrid de entreguerras, en las que la parada en el café-bar o en la taberna, el flirteo más o menos explícito en el dancing y el cierre de la velada en una casa de citas próxima constituía un ritual bastante habitual. Los y también las jóvenes trabajadoras de la capital salían a divertirse por la ciudad en sus ratos de tiempo libre y lo hacían de un modo y en unos lugares que solo empezaron a estar disponibles en el contexto que abrieron las grandes urbes como Madrid en los años posteriores a la Primera Guerra Mundial. En este momento, los hábitos de ocio de la juventud popular madrileña estaban empezando a incorporar nuevas prácticas asociadas a los locales públicos modernos y las nuevas fórmulas de ocio que empezaron a aparecer en la ciudad. Estas prácticas terminarían por transformar radicalmente algunas de las características que habían definido las formas de entretenimiento de los y sobre todo de las jóvenes de clases populares en el pasado.

Las condiciones que hicieron posible este tipo de rutinas y conductas fueron creadas al calor del proceso de transformación y modernización que experimentó la capital española en múltiples ámbitos en las décadas de los veinte y los treinta. Sin

87. AGA, Justicia, leg. (07) 41.010, top. 43/37.606-38.309, caja 7654. 
duda, una de ellas fue el nuevo talante comercial y cosmopolita que había empezado a adquirir la infraestructura de ocio de la ciudad en aquellos años, un talante que creó nuevas oportunidades para el entretenimiento juvenil urbano, al poner a disposición de los chicos y chicas de clases populares toda una red de locales de baile a precios y horarios compatibles con sus pautas de vida y sus condiciones de existencia. La disponibilidad de dancings como La Gruta era necesaria para que jóvenes como Dolores y otras tantas protagonistas de los sumarios judiciales pudieran acudir a ellos tal y como lo hicieron. Pero, además, la configuración de este entramado de entretenimientos baratos (bailes, cines, cafés-tupí, bares, tabernas, etc.) no era solo imprescindible para conformar estos patrones de ocio fuera del hogar y del entorno inmediato del vecindario, sino que fue también una condición sine qua non para que estos jóvenes desarrollaran pautas y fórmulas de interacción social y sexual como las que hemos observado más arriba.

Los, pero especialmente las jóvenes de los barrios populares madrileños contribuyeron así, con sus conductas y actitudes, a reformular la nueva cultura del ocio que brotó de aquel contexto específico de los años de entreguerras. Por un lado, gracias a sus particulares condiciones de existencia, estas jóvenes trabajadoras fueron pioneras en la ocupación y uso de los nuevos entretenimientos comerciales, y reforzaron y normalizaron, así, nuevos valores relacionados con la participación femenina en el ocio y el espacio público, y con el derecho de las mujeres a la diversión, el placer y la realización personal. Por otro lado, al ser partícipes de las nuevas dinámicas de encuentro e interacción social y sexual que los nuevos locales de ocio llevaban adscritas, ayudaron asimismo a ensanchar los márgenes de lo considerado normal o respetable en lo que se refiere al flirteo y los intercambios sexuales dentro de los espacios de ocio, pero también fuera de ellos, redefiniendo el rol que jugaba el sexo en las relaciones de género y su consideración en la construcción de los modernos modelos de feminidad y masculinidad. Con todo ello, las muchachas como Dolores Domínguez, Encarnación Rubira, Teresa Ortega, Eugenia Ramírez, Pilar Ayala, Mercedes Domau, Josefa García o Milagros Herrera, así como otras tantas desconocidas que rompieron amarras con el pasado en otros terrenos distintos a aquellos de otras pioneras pertenecientes a las capas sociales más privilegiadas, contribuyeron a reformular y construir la nueva cultura heterosocial del entretenimiento moderno, en la que, primero, la participación de las mujeres y, segundo, la presencia implícita o explícita del sexo, constituyeron, desde entonces hasta hoy, dos de sus ingredientes fundamentales. 